\title{
A coupled THC model of the FEBEX in situ test with bentonite swelling and chemical and thermal osmosis
}

\author{
${\text { Liange } \text { Zheng }^{{ }^{*}} \text {, Javier Samper }}^{2}$, and Luis Montenegro ${ }^{2}$
}

(1) Lawrence Berkeley National Laboratory, 1 Cyclotron Road, Berkeley, CA, 94720, USA.

(2) E. T. S. Ingenieros de Caminos, Canales y Puertos, Universidad de Coruña, Campus de Elviña s/n, 15192 La Coruña; jsamper@udc.es; lmontenegro@udc.es

*Corresponding author. E-mail address: lzheng@lbl.gov

\begin{abstract}
The performance assessment of a geological repository for radioactive waste requires quantifying the geochemical evolution of the bentonite engineered barrier. This barrier will be exposed to coupled thermal (T), hydrodynamic (H), mechanical (M) and chemical (C) processes. This paper presents a coupled THC model of the FEBEX (Full-scale Engineered Barrier EXperiment) in situ test which accounts for bentonite swelling and chemical and thermal osmosis. Model results attest the relevance of thermal osmosis and bentonite swelling for the geochemical evolution of the bentonite barrier while chemical osmosis is found to be almost irrelevant. The model has been tested with data collected after the dismantling of heater 1 of the in situ test. The model reproduces reasonably well the measured temperature, relative humidity, water content and inferred geochemical data. However, it fails to mimic the solute concentrations at the heater-bentonite and bentonite-granite interfaces because the model does not account for the volume change of bentonite, the $\mathrm{CO}_{2}(\mathrm{~g})$ degassing and the transport of vapor from the bentonite into the granite. The inferred $\mathrm{HCO}_{3}{ }^{-}$and $\mathrm{pH}$ data cannot be explained solely by solute
\end{abstract}


transport, calcite dissolution and protonation/deprotonation by surface complexation, suggesting that such data may be affected also by other reactions.

Keywords: THC model, bentonite, FEBEX in situ, nuclear waste, osmosis, bentonite swelling

\section{INTRODUCTION}

Compacted bentonite is foreseen in several countries as a backfill and sealing material for high-level radioactive waste (HLW) disposal. Various in situ experiments have been conducted to demonstrate the technical feasibility of HLW disposal and study the physical phenomena and the chemical reactions taking place at the bentonite barrier. They include: the LOT experiment at the Äspö underground research laboratory (URL) in Sweden (Karnland et al., 2000; Arcos et al., 2003), the Ophelie mock-up test performed at the HADES URL in Belgium (Verstricht et al., 2007), and the FEBEX (Full-scale Engineered Barrier EXperiment) project (ENRESA, 2000, 2006a). FEBEX is a demonstration and research project dealing with the engineered barrier system (EBS) designed for sealing and containment of waste in a radioactive waste repository (ENRESA, 2000). FEBEX is based on the Spanish reference concept for the disposal of radioactive waste in crystalline rocks. Besides laboratory experiments, FEBEX includes two large-scale tests: the mock-up test being carried out at CIEMAT (Research Centre for Energy, Environment and Technology) facilities in Madrid, Spain (Martín and Barcala, 2005) and the in situ test at the Grimsel underground laboratory (Switzerland) (Alonso and Ledesma, 2005; ENRESA, 2000; 2006a).

The appropriate performance of a HLW repository relies on the geochemical stability of the bentonite buffer (SKB, 1983). Geochemical models for the bentonite are useful tools to interpret experimental results and perform long term predictions. Examples of such models include the bentonite geochemical model of Arcos et al. (2003) for the LOT experiment, the 
models tested within the DECOVALEX Project (Tsang et al., 2009), and the coupled thermal, hydrodynamic and chemical (THC) models of the FEBEX bentonite (ENRESA, 2000; 2006c; Samper et al., 2008a,b; Zheng et al., 2010). The FEBEX in situ experiment started in February 1997. Heater 1 of this test was dismantled in the summer of 2002 and provided a wealth of THC data has been used to test the predictions of THC models. Geochemical data were obtained from aqueous extract tests performed at low solid-to-liquid ratios (ENRESA, 2006c). The interpretation of these data requires using hydrogeochemical models to account for the geochemical reactions suffered by the bentonite samples during the aqueous extraction tests (Zheng et al., 2008a). These inferred data were compared to THC model predictions by Samper et al., (2008a) who found significant discrepancies for most chemical species, and especially for $\mathrm{SO}_{4}{ }^{2-}$ and $\mathrm{HCO}_{3}{ }^{-}$. The limitations of the THC model of Samper et al. (2008a) could be attributed to bentonite swelling and coupled phenomena such as chemical and thermal osmosis which were found to be relevant for reactive solute transport through FEBEX bentonite by Zheng and Samper (2008) for the FEBEX mock up test and Zheng et al. (2010) for a small-scale $(13 \mathrm{~cm})$ heating and hydration lab test.

Here we present a model for the FEBEX in situ test which improves the THC model of Samper et al. (2008a) by accounting for: 1) The swelling of bentonite by a state-surface method, 2) Proton surface complexation reactions with several types of sorption sites, and 3) Thermal and chemical osmosis. The paper starts with a description of the FEBEX in situ test. Then, the conceptual and mathematical models are presented. Geochemical data obtained after partial dismantling of the test are described afterwards. Then, model results and their comparison with measured data are presented. Model uncertainties are discussed in detail. The paper ends with the main conclusions. Appendix A presents the governing equations. 


\section{FEBEX IN SITU TEST}

The FEBEX in situ test is being performed in a gallery excavated in the granitic Grimsel URL operated by NAGRA in Switzerland (ENRESA, 2000). The test consists of five basic units: the drift, the heating system, the clay barrier (bentonite), the instrumentation and the monitoring and control system. The drift is $70.4 \mathrm{~m}$ long and $2.28 \mathrm{~m}$ in diameter. The test area which was sealed with a concrete plug is located at the last $17.4 \mathrm{~m}$ of the drift where heaters, bentonite and instrumentation were installed. The main elements of the heating system are two heaters (1 and 2), separated horizontally by $1 \mathrm{~m}$, which simulate full-sized canisters. Heaters were placed inside a cylindrical steel liner. Each heater is made of carbon steel, measures $4.54 \mathrm{~m}$ in length, $0.9 \mathrm{~m}$ in diameter and has a wall thickness of $0.1 \mathrm{~m}$. Heaters were operated at a constant power output of $1200 \mathrm{~W} /$ heater during the first 20 days and 2000 W/heater for the following 33 days. Afterwards, heaters were switched to a constant-temperature control mode to maintain a maximum temperature of $100^{\circ} \mathrm{C}$ at the steel liner/bentonite interface.

The clay barrier is made of blocks of highly compacted bentonite, situated in vertical sections normal to the axis of the tunnel. A layout of the in situ test is shown in Fig. 1. The average values of the initial dry density and the water content of bentonite blocks are $1.7 \mathrm{~g} / \mathrm{cm}^{3}$ and $14.4 \%$, respectively.

The in situ test began in February 27th, 1997. Heater 1 was switched-off in February 2002 and dismantled from May to September 2002. A comprehensive post-mortem bentonite sampling and analysis program was performed on the solid and liquid phases to check the 
physical and chemical changes induced by the combined effect of heating and hydration and test THM and THC model predictions (ENRESA 2006a,b,c).

\section{CONCEPTUAL AND NUMERICAL MODEL}

\subsection{Conceptual model}

\subsubsection{Flow and transport}

The mathematical formulation of the flow and transport model of the FEBEX in situ test is similar to that used by Zheng et al. (2010) for a small-scale heating and hydration experiment performed in a sample of FEBEX bentonite. A brief summary of the physical formulation and the main assumptions is presented here. The multiphase flow formulation of the model accounts for: 1) Coupled flow of liquid water due to hydraulic, chemical and thermal gradients, 2) Vapor advection and diffusion, 3) Advection and diffusion of 'dry' air, 4) Flow of air dissolved in the water (advection), and 5) Heat convection through the liquid and gaseous phases and heat conduction through the solid, liquid and gaseous phases. It is assumed that there is equilibrium between: 1) The liquid and the vapor phase according to the Kelvin equation, 2) The temperature of the phases with instantaneous dissipation of thermal perturbations; 3) Air in the liquid and gaseous phases, and 4) Vapor and 'dry' air. Air partial pressure is related to the mass fraction of the air in the liquid phase according to Henry’s law. The state surface equation proposed by Lloret and Alonso (1995) is used to calculate bentonite swelling.

The governing equations are presented in Appendix A. The details of their implementation in the computer code INVERSE-FADES-CORE are described by Navarro and Alonso (2000) and Zheng et al. (2010). 


\subsubsection{Thermal and chemical osmosis}

The flux of fluid caused by thermal osmosis $\left(\mathrm{kg} / \mathrm{m}^{2} / \mathrm{s}\right), v_{\text {to }}$, can be written as (Dirksen, 1969):

$$
v_{t o}=-k_{T} \frac{\rrbracket T}{\llbracket x}
$$

where $k_{T}$ is the thermo-osmosis coefficient $(\mathrm{kg} / \mathrm{m} / \mathrm{s} / \mathrm{K})$, and $T$ is temperature $(\mathrm{K})$. The liquid flux caused by thermal osmosis is added to the Darcian terms (Ghassemi and Diek, 2002; Zhou et al., 1999).

The liquid flux induced by chemical osmosis $\left(\mathrm{kg} / \mathrm{m}^{2} / \mathrm{s}\right), J_{c o}$, is written in a form similar to Darcy’s law according to (Keijzer et al., 1999; Keijzer and Loch, 2001; Soler, 2001):

$$
J_{c o}=\operatorname{rsK} \frac{\rrbracket p_{h}}{\llbracket x}
$$

where $\rho$ is the water density $\left(\mathrm{kg} / \mathrm{m}^{3}\right), K$ is the hydraulic conductivity $(\mathrm{m} / \mathrm{s}), \sigma$ is the reflection coefficient (Keijzer et al., 1999) or the coefficient of osmotic efficiency (Soler, 2001) and $\pi_{h}$ is the osmotic pressure head $(\mathrm{m})$ which is defined as:

$$
p_{h}=\frac{p}{r g}
$$

where $\pi$ is the osmotic pressure which for dilute solutions can be calculated from (Soltanieh and Gill, 1981):

$$
p=-\frac{R T}{V_{w}} \ln \left(a_{w}\right)
$$


where $R$ is the gas constant and $V_{w}$ and $a_{w}$ are the molar volume and the activity of water, respectively. According to Garrels and Christ (1965), the activity of the water can be calculated from:

$$
a_{w}=1-V_{w} \stackrel{\circ}{\mathbf{a}_{i}} \frac{C_{i}}{W_{i}}
$$

where $C_{i}$ and $W_{i}$ are the concentration $\left(\mathrm{kg} / \mathrm{m}^{3}\right)$ and the molar weight of the $i$-th species, respectively.

The volumetric liquid flux, $\mathbf{q}^{l}$, includes the classical Darcian term and the chemical and thermal osmotic terms:

$$
\mathbf{q}^{l}=-\frac{\mathbf{k}^{i l} k^{r l}}{m}\left(\tilde{\mathbf{N}} p^{l}+r^{l} X_{l}^{w} g \tilde{\mathrm{N}} z\right)-k_{T} \tilde{\mathrm{N}} T+s \frac{\mathbf{k}^{i l} k^{r l}}{m} \tilde{\mathbf{N}} p_{h}
$$

where $p^{l}$ is the liquid pressure $(\mathrm{Pa}), \boldsymbol{k}^{i l}$ is the intrinsic permeability tensor of the liquid $\left(\mathrm{m}^{2}\right), k^{r l}$ is the relative permeability of the liquid, $\mu^{l}$ is the viscosity of the liquid $(\mathrm{kg} / \mathrm{m} / \mathrm{s})$ and $z$ is the elevation (m).

\subsubsection{Bentonite swelling}

The swelling of unsaturated bentonite caused by hydration can be calculated in several ways. One of them involves a constitutive equation relating bentonite deformation to the distance between two montmorillonite layers based on the Gouy-Chapman diffuse double layer (DDL) theory (e.g. Komine and Ogata,1996; 2003; Schanz and Tripathy, 2009). This method, however, can only be applied to a limited range of swelling pressures (Komine and Ogata, 1996) and particle spacings (Komine and Ogata, 2003) and has a limited applicability to highly-compacted bentonite such as FEBEX bentonite (Schanz and Tripathy, 2009). Xie et al. (2004) performed an upscaling procedure to relate the porosity to the thickness of DDL and incorporated such a 
relationship in a chemo-hydro-mechanical model. Their model, however, is restricted to isothermal free swelling/shrinking. Swelling can be computed with elastoplastic models (Gens and Alonso, 1992; Thomas and He, 1998) such as the Barcelona Basic Model (BBM) (Alonso et al., 1990) and the Barcelona Expansive Model (BExM) (Alonso et al., 1999). The elastoplastic model has been further extended to account for macro- and micro-structures of expansive clays (Alonso et al., 1999; Thomas and Cleall, 1999; Sánchez et al., 2005). Elastoplastic models require many parameters some of which are difficult to obtain experimentally. To overcome the difficulties of these models, some researchers have resorted to simple models such as the statesurface approach to simulate bentonite swelling. Nguyen et al. (2005) used the state-surface approach to interpret successfully a swelling pressure test.

The simple state-surface approach is sufficient for the THC geochemical reactive transport model. The following state-surface expression of Lloret and Alonso (1995) was adopted here to model bentonite swelling:

$$
e=A+B \ln \sigma^{\prime}+C \ln \left(\psi+p^{a}\right)+D \ln \sigma^{\prime} \ln \left(\psi+p^{a}\right)
$$

where $e$ is the void ratio which is equal to the volume of voids divided by the volume of the solids; $p^{a}$ is the atmospheric pressure $(\mathrm{Pa}), \sigma^{\prime}$ is the mean effective stress $(\mathrm{Pa}) ; \psi$ is the suction (Pa), and A, B, C and D are empirical constants which for the FEBEX compacted bentonite are equal to $\mathrm{A}=0.76, \mathrm{~B}=-0.052446, \mathrm{C}=-0.0406413$ and $\mathrm{D}=0.00479977$ (Nguyen et al., 2005).

\subsubsection{Solute transport and chemical reactions}

Multicomponent solute transport mechanisms include: advection, molecular diffusion, and mechanical dispersion (see Zheng et al., 2010 for more details). Chemical reactions include: 
aqueous complexation, acid-base, mineral dissolution/precipitation, cation exchange and surface complexation. The chemical system is defined in terms of the following primary species: $\mathrm{H}_{2} \mathrm{O}$, $\mathrm{H}^{+}, \mathrm{Ca}^{2+}, \mathrm{Mg}^{2+}, \mathrm{Na}^{+}, \mathrm{K}^{+}, \mathrm{Cl}^{-}, \mathrm{SO}_{4}{ }^{2-}, \mathrm{HCO}_{3}{ }^{-}$and $\mathrm{SiO}_{2}(\mathrm{aq})$. Aqueous complexes and minerals considered in the chemical system and their equilibrium constants at $25{ }^{\circ} \mathrm{C}$ were taken from the database of EQ3/6 (Wolery, 1992). They are listed in Table 1. Significant aqueous complexes were selected from speciation runs performed with EQ3/6 (Wolery, 1992). Calcite, anhydrite and chalcedony are assumed at chemical equilibrium. Cation exchange reactions are modeled with the Gaines-Thomas convention. Their selectivity coefficients are listed in Table 1 . Three types of protolysis sites $\mathrm{S}^{\mathrm{S}} \mathrm{OH}, \mathrm{S}^{\mathrm{W} 1} \mathrm{OH}$ and $\mathrm{S}^{\mathrm{W} 2} \mathrm{OH}$ (Bradbury and Baeyens, 1997) are considered for surface complexation reactions. These reactions and their protolysis constants are also listed in Table 1.

\subsection{Computer code}

Model predictions of the in situ test have been performed with the code INVERSEFADES-CORE (Zheng and Samper, 2005) which solves both direct and inverse multiphase flow and multicomponent reactive transport problems in deformable porous media. INVERSEFADES-CORE integrates FADES (Navarro and Alonso, 2000), CORE ${ }^{2 \mathrm{D}}$ (Samper et al., 2003; 2009) and the inverse methodology of INVERSE-CORE of Dai and Samper (2004). Besides the features of these codes, INVERSE-FADES-CORE accounts for chemical-hydrodynamic and thermal-hydrodynamic couplings. The state variables are liquid pressure, gas pressure, temperature and displacement. The governing equations are solved with a Petrov-Galerkin finite element method (Navarro and Alonso, 2000). The resulting nonlinear algebraic equations are solved with an iterative Newton-Raphson method. Reactive transport equations are solved with a 
sequential iteration method to compute the concentrations of primary species (Samper et al., 2009). The inverse problem is solved by minimizing a generalized least-squares criterion with a Gauss-Newton-Levenberg-Marquardt method. The forward routines of INVERSE-FADESCORE have been widely verified by analytical solutions (Samper et al., 2003; Samper et al., 2008a) and applied to the simulation of THM problems (Navarro and Alonso, 2000) and THC laboratory and in situ tests (ENRESA, 2006c; Samper et al., 2008a; Zheng et al., 2008b). The convergence, uniqueness and stability of the inverse algorithm have been analyzed by Dai and Samper (2004) and Zheng and Samper (2005). The code has proven to provide optimum estimates for a wide range type of THMC parameters (Zheng and Samper, 2004, 2005; Zheng et al., 2010).

\subsection{Numerical model}

The hydration rate of bentonite is deemed to be relatively homogeneous along the gallery because the permeability of bentonite which is several orders of magnitude smaller than that of the granite limits the hydration rate. The benchmark models of Alonso et al. (2005) provide additional evidence for the axial symmetry for sections near the central sections of the heaters. Our model assumes axial symmetry because it is focused on the interpretation of the geochemical data from sections 28 and 29 which are not far from the central section of heater 1 (Figure 1). The spatial domain is discretized with a finite element mesh containing 614 nodes and a single row of 307 rectangular elements (Fig. 2). The model considers two material zones for the bentonite and granite. The first two nodes (1 and 2) are located on the external wall of the heater $(\mathrm{r}=0.47 \mathrm{~m})$. Bentonite is located within $0.47 \mathrm{~m}<\mathrm{r}<1.135 \mathrm{~m}$ and is discretized with 220 nodes. The remaining 392 nodes simulate the granite. The last two nodes, 613 and 614, are 
located at $\mathrm{r}=50 \mathrm{~m}$ from the central axis of the heater 1 . The model is run for 1930 days until the dismantling of the heater 1 .

The initial temperature is uniform and equal to $12^{\circ} \mathrm{C}$. A constant temperature of $97^{\circ} \mathrm{C}$ is prescribed at the heater-bentonite interface $(\mathrm{r}=0.45 \mathrm{~m})$ while the temperature at the external boundary $(\mathrm{r}=50 \mathrm{~m})$ is assumed constant and equal to its initial value of $12{ }^{\circ} \mathrm{C}$ because the thermal perturbation induced by the heaters does not extend to such boundary. The model does not account for the initial constant-power heating phase of 53 days.

The bentonite has initially a gravimetric water content of $14 \%$ which corresponds to a saturation degree of $59 \%$ and a suction of $1.11 \cdot 10^{5} \mathrm{kPa}$. The boundary conditions for flow include: 1) No flow at $\mathrm{r}=0.45 \mathrm{~m}$ and 2) A prescribed liquid pressure of $700 \mathrm{kPa}$ at $\mathrm{r}=50 \mathrm{~m}$ (see Fig. 2). The initial stress in the bentonite is assumed to be isotropic and equal to $250 \mathrm{kPa}$. A prescribed radial stress of $2.8 \cdot 10^{4} \mathrm{kPa}$ is used at $\mathrm{r}=50 \mathrm{~m}$ while it is assumed that the displacement is zero at $\mathrm{r}=0.45 \mathrm{~m}$ (ENRESA, 2006b,c).

The FEBEX in situ test was not designed to be air-tight. Therefore, nothing prevented gas from flowing in or out the test section at the early stages of the test. It is believed, nonetheless, that bentonite swelling sealed most of the gaps and voids of the bentonite barrier except near the heater, making it difficult for the gas to flow through the concrete plug. It is assumed in the model that the system is closed for gaseous phases. This means that there is neither gas flux across external boundaries nor prescribed gas pressures. The gaseous phase in the granite and the bentonite is simulated as a trapped phase overlapping the liquid phase.

Changes in the intrinsic permeability caused by changes in the porosity are computed using the ratio of permeabilities calculated from the Kozeny-Carman (KC) equation (Bear, 1972): 


$$
K=K_{0} \frac{\phi^{3}}{(1-\phi)^{2}} \frac{\left(1-\phi_{0}\right)^{2}}{\phi_{0}^{3}}
$$

where $\mathrm{K}_{0}\left(\mathrm{~m}^{2}\right)$ and $\phi_{0}$ are the reference values of bentonite permeability and porosity, respectively which are equal to $\mathrm{K}_{0}=3.75 \cdot 10^{-21} \mathrm{~m}^{2}$ and $\phi_{0}=0.41$. Although it could be argued that the $\mathrm{KC}$ equation in (8), which was initially derived mainly for granular materials, might not be adequate for low-permeability high-porosity materials such as bentonites, the results reported by Chapuis and Aubertin (2003) show that the KC equation predicts reasonably well the saturated hydraulic conductivity of most soils. Mauran et al. (2001) showed also that the KC equation can be safely used for large-porosity media. Recently, Odong (2007) found that the KC equation was the best estimator of the hydraulic conductivity from grain-size data for a wide range of soils. Taking into account that changes in porosity in the in situ test are smaller than $20 \%$, the use of the KC equation to relate intrinsic permeability to porosity in the model does not introduce large errors.

The permeability $\mathrm{K}_{0}$ in Equation (8) is the most important parameter for the hydrodynamic response of the bentonite when exposed to the combined effect of heating and hydration. Here, the optimum value of $\mathrm{K}_{0}=3.75 \cdot 10^{-21} \mathrm{~m}^{2}$ was derived by fitting measured water content data and chemical concentrations. This value is larger than the value of $\mathrm{K}_{0}=2 \cdot 10^{-21} \mathrm{~m}^{2}$ reported by Chen et al. (2009) from a THM model of the FEBEX in situ test. Differences in the calibrated values of $\mathrm{K}_{0}$ are due to differences in the constitutive relationships such as the relative permeability and to the fact that the model of Chen et al. (2009) did not consider chemical concentration data in their calibration. Our calibrated value of $K_{0}$ for the in situ test is slightly larger than that calibrated by Zheng and Samper (2008) for the FEBEX mock-up test $\left(\mathrm{K}_{0}=\right.$ $3.51 \cdot 10^{-21} \mathrm{~m}^{2}$ ). The small difference in the calibrated values of $\mathrm{K}_{0}$ in the mock up and in situ tests could be attributed to the fact that the bentonite barrier in the mock up test was flooded with 
water before switching on the heaters to promote bentonite swelling and seal the joints between bentonite blocks. In the FEBEX in situ test, however, block joints were not pre-sealed. Therefore, the hydration rate of the bentonite barrier in the in situ test is probably faster than that of the mock-up test.

The retention curve for bentonite is similar to that of Villar et al. (2008) and Sánchez et al. (2011) and is given by:

$$
S_{1}=\frac{\left(1-9.1 \cdot 10^{-10} \psi\right)^{1.1}}{\left[\left(1+5 \cdot 10^{-8} \psi\right)^{1.22}\right]^{0.18}}
$$

where $\psi$ is the suction $(\mathrm{Pa})$, and $S_{l}$ is the saturation degree. Experimental results have shown that the influence of temperature on retention curve is often small (Lloret et al., 2004).

The mechanical deformation of granite is calculated with the following linear elastic model:

$$
d \varepsilon=\frac{\alpha}{1+e^{0}} \cdot d \sigma^{*}
$$

where $\varepsilon$ is the strain vector, $e^{0}$ is the initial void ratio, and $\alpha$ is an empirical constant which is taken equal to to $10^{-4} \mathrm{kPa}^{-1}$.

Hydrodynamic, thermal and mechanical parameters for the bentonite and the granite are listed in Tables 2 and 3. A constant gas viscosity is used to simplify the calculations because the change of the gas viscosity with temperature is not expected to have a significant impact in the evolution of the system.

The permeability of the granite is equal to $8 \cdot 10^{-18} \mathrm{~m}^{2}$. This value is within the range of equivalent permeabilities of the granite calculated by Martínez-Landa and Carrera (2005) from hydraulic tests performed around the FEBEX gallery at the Grimsel site. Alonso et al. (2005) and Chen et al. (2009) used a much larger value (of $5 \cdot 10^{-19} \mathrm{~m}^{2}$ ). We claim that the permeability of the 
granite is not relevant for the hydrodynamic evolution of the bentonite barrier because the hydration of the bentonite is controlled by the permeability of the bentonite.

The initial chemical compositions of the granite and the FEBEX bentonite pore waters (Fernández et al., 2001) are listed in Table 4. This table shows also the initial mineral volume fractions, the concentrations of exchanged cations, and the site occupancies of the surface complexation sites for the bentonite and the granite.

The effective diffusion for $\mathrm{Cl}^{-}$was taken from Cormenzana et al. (2004) and is equal to $9.3 \cdot 10^{-13} \mathrm{~m}^{2} / \mathrm{s}$. The effective diffusion for $\mathrm{SO}_{4}{ }^{2-}$ was taken from García-Gutiérrez (2006) and is equal to $1.1 \cdot 10^{-13} \mathrm{~m}^{2} / \mathrm{s}$. There are no available data for the effective diffusion of the rest of the chemical species. All species are assumed to have the same effective diffusion of $6.1 \cdot 10^{-12} \mathrm{~m}^{2} / \mathrm{s}$ which was derived from the calibration of heating and hydration laboratory experiments (ENRESA, 2006c).

There are no dispersivity data for granite. The results of the sensitivity analyses to granite dispersivity show that this parameter affects mostly the back diffusion of solutes from the bentonite into the granite (ENRESA, 2000; 2006c). Given the small value of the Peclet number of the bentonite, model results are not sensitive to the bentonite dispersivity. To prevent numerical oscillations near the bentonite-granite interface, the longitudinal dispersivities were taken equal to 0.01 for the bentonite and $0.2 \mathrm{~m}$ for the granite. These values ensure that the grid Peclet number is much smaller than 2 . 


\section{GEOCHEMICAL DATA AFTER PARTIAL DISMANTLING OF THE IN SITU TEST}

\subsection{Location of bentonite samples}

Bentonite samples were taken from vertical sections normal to the axis of the tunnel. Samples were taken along several radii in each section. Bentonite samples were taken for THC analyses from three sections in the heater zone (\# 19, 28 and 29), a section in the zone between the concrete seal and the heater 1 (\# 12) and a section in contact with the concrete seal (\# 7) (see Fig. 1).

Each sampling section consists in an outer, central and inner layer of bentonite blocks. The location of bentonite blocks in section 29 collected after dismantling of heater are shown in Fig. 3. A total of 9 bentonite blocks were sampled at several radial distances. Bentonite blocks were preserved immediately after their extraction in plastic films, two layers of aluminized PETsheets and vacuum-sealed plastic bags. The first PET-sheet was vacuum sealed after flushing nitrogen in it. Protection against mechanical actions was used to ensure the integrity of the material (ENRESA, 2006a).

\subsection{Inference of pore water composition from aqueous extract data}

Much effort has been made during recent years to improve the water extraction methods, develop numerical interpretation methods and achieve consistency of experimental data and geochemical modeling (Sacchi et al., 2001; Bradbury and Baeyens, 2003; Pearson et al., 2003; Fernández et al., 2004). Preserving in situ conditions of core samples is difficult. A general discussion of perturbations caused by sampling, storage, preparation and extraction techniques is 
given by Sacchi et al. (2001) and Pearson et al. (2003). Aqueous extract tests (AET) have been used to obtain pore water chemistry for compacted FEBEX bentonite. AET is a method to quantify the total content of soluble salts of a clay sample. An 1:R AET consists on adding to a mass $M_{s}$ of powdered clay sample a mass of distilled water equal to $R$ times $M_{s}$. Clay sample and water are stirred during a period of time of usually 2 days during which equilibration of water and clay sample is allowed. Chemical analyses are performed on the supernatant solution after phase separation by centrifugation (Sacchi et al., 2001). In addition to dilution, chemical reactions take place during pore water extraction which change the concentrations of dissolved species in a complex nonlinear manner. This makes it difficult to derive the chemical composition of the original pore water from the aqueous extract data (Bradbury and Baeyens, 1998; Sacchi et al., 2001). The inference of dissolved concentration for reactive species requires geochemical modeling based on mineralogical data (Bradbury and Baeyens, 1997, 1998, 2003; Pearson et al., 2003; Fernández and Rivas, 2005; Zheng et al., 2008a). The methodology used here to infer bentonite pore water chemical composition from AET data is based on the definition of a conceptual geochemical model (CGM) for the clay-water system. A CGM for a clay sample is defined in terms of relevant chemical reactions taking place during aqueous extraction. Identification of the CGM requires knowing: 1) The list of relevant aqueous complexes, 2) Relevant mineral phases, their initial volume fractions and equilibrium constants, 3) Cation exchange reactions, CEC and cation selectivities, and 4) Relevant gas phases, pressures and conditions (open or closed). The method starts from an initial CGM and a guess of sample pore water concentrations, $c_{i}$. Inverse modeling accounts for the perturbations caused by the aqueous extraction and computes the concentrations of the aqueous extracts. The optimum estimates of dissolved concentrations are those that minimize the differences between measured 
and calculated aqueous extract concentrations. Large deviations of model results from measured data may show the need to modify or update the CGM. The $\mathrm{pH}$ and the concentrations of the major anions and cations of the original clay sample are estimated. Additional details of the inverse AET interpretation can be found in Zheng et al. (2008a).

Aqueous extract tests and cation exchange population are available in sections 19, 28 and 29 (Fernández and Rivas, 2003). Aqueous extract data from sections 29 and 19 (see Fig. 1) were interpreted by inverse geochemical modeling and used to test the model predictions.

\section{MODEL RESULTS}

\subsection{Thermal and hydrodynamic results}

The model reproduces properly the radial distribution of computed temperatures in the bentonite and granite at 1827 days which coincides with the date in which heater 1 was switched off (Fig. 4). The fit to measured temperatures at the dismantling time ( $\mathrm{t}=1930$ days) is worse because the dismantling of the concrete plug and the bentonite buffer induced a threedimensional heat re-distribution which is not taken into account in the 2D axisymmetric model presented here (Fig. 5). Measured and calculated relative humidities after 1827 and 1930 days are shown in Fig. 6 and 7. The model overpredicts the measured relative humidities near the heater probably because the model does not account for phase adsorption which should lower the vapor pressure and the relative humidity. Therefore, failing to account for phase adsorption leads to too-high vapor pressures and relative humidities. The computed spatial distributions of porosities at several times reveal bentonite swelling near the granite-bentonite interface and the thermal shrinkage near the heater (Fig. 8). Note that the Fig. 8 does not include the porosity changed induced by mineral dissolution/precipitation. 
Figure 9 shows the testing of model predictions with measured gravimetric water contents at sections 19, 28 and 29 after 1930 days. Model results fit data measured in sections 19 and 28 but overestimate slightly the data in section 29 near the heater. This figure shows also the water content computed with the previous THC model of Samper et al. (2008a). Clearly, the current model outperforms the previous THC model in the calculation of water contents because it accounts for osmosis and swelling. It is noteworthy that there is a discrepancy between measured and calculated water content near the bentonite-granite interface. This discrepancy might be caused by the limitation of the model which does not account for the volume change of bentonite due to the existence of a gap at the bentonite-granite interface and the heterogeneities in the granite.

\subsection{Chemical results}

Figures 10 to 17 show the computed concentrations of the chemical species after 1930 days. Model predictions are compared to data inferred from aqueous extract data at sections 19 and 29. The comparison of model calculations and inferred aqueous extract data show that the model reproduces the trends of the most part of the inferred data, but there are some deviations at the heater-bentonite and bentonite-granite interfaces.

Fig. 10 shows the measured and computed spatial distribution of $\mathrm{Cl}^{-}$concentrations after 1930 days and the comparison with inferred aqueous extract data (sections 19 and 29). The inferred $\mathrm{Cl}^{-}$concentration is very small close to the bentonite-granite interface and then shows a plateau with concentrations similar to the initial bentonite $\mathrm{Cl}^{-}$concentration (Figure 10). Computed $\mathrm{Cl}^{-}$concentrations are largest near the heater due to bentonite porewater evaporation and smallest at the granite-bentonite interface due to the hydration of the buffer with granite pore 
water which has a concentration smaller than that of the bentonite (see Table 4). The inward displacement of the hydration front, water evaporation at the heater-bentonite and solute diffusion govern the spatial distribution of this conservative species.

Computed concentrations with, and without bentonite swelling and osmosis are markedly different. Failing to account for bentonite swelling and osmosis leads to a fast and relatively uniform hydration rate of bentonite. As a result, the model which disregards swelling and osmosis overestimates the inferred $\mathrm{Cl}^{-}$concentration near the bentonite-granite interface and cannot reproduce the measured concentration plateau (see Figure 10). Adjusting the initial $\mathrm{Cl}^{-}$ concentration cannot overcome such misfit. Bentonite swelling and osmosis retards the hydration of the bentonite buffer. Therefore, the model with swelling and osmosis catches the trend of inferred $\mathrm{Cl}^{-}$data and fits the measured data by adjusting the initial $\mathrm{Cl}^{-}$concentration from 0.16 to $0.24 \mathrm{~mol} / \mathrm{L}$.

Dissolved cations $\left(\mathrm{Ca}^{2+}, \mathrm{Mg}^{2+}, \mathrm{Na}^{+}, \mathrm{K}^{+}\right)$show similar trends to those of $\mathrm{Cl}^{-}$. Mineral dissolution/precipitation and cation exchange affect their concentrations. Fig. 11 shows the comparison of the computed calcium spatial distribution with the inferred aqueous extract data of sections 19 and 29 at 1930 days. Water evaporation near the heater causes an increase in the concentrations which in turn induces calcite precipitation. Consequently, the concentration of dissolved $\mathrm{Ca}^{2+}$ decreases at the heater-bentonite interface. Dissolved $\mathrm{Mg}^{2+}$ (Fig. 12), $\mathrm{Na}^{+}$(Fig. 13) and $\mathrm{K}^{+}$(Fig. 14) show also a pattern of large concentrations near the heater and small concentrations near the bentonite-granite interface. Computed concentrations reproduce the trends of inferred aqueous extract data and generally fit the inferred aqueous extract data of section 19 better than those of section 29. 
Fig. 15 shows the model predictions of $\mathrm{SO}_{4}{ }^{2-}$ concentrations at 1930 days as well as the comparison with inferred aqueous extract data at sections 29 and 19 . Inferred $\mathrm{SO}_{4}{ }^{2-}$ aqueous extract data in section 29 show fluctuations while those in section 19 show a more stable trend. Computed $\mathrm{SO}_{4}{ }^{2-}$ concentrations underestimate inferred aqueous extract data near the bentonitegranite interface. This could be attributed to uncertainties in the initial amount of gypsum in the bentonite.

While the inferred concentrations of most chemical species decrease close to the bentonite-heater interface, the computed concentrations increase sharply near such interface (see Figures 10 to 15). For reactive species, this discrepancy could be explained by accounting for additional mineral phases that could precipitate reactive species near the heater. For $\mathrm{Cl}^{-}$, however, anion exclusion is most likely to explain this discrepancy.

The hydration of bentonite with granite water induces the dissolution of calcite. Consequently, the computed $\mathrm{HCO}_{3}{ }^{-}$concentration increases near the bentonite-granite interface (Fig. 16). There is a front of high concentrations of $\mathrm{HCO}_{3}{ }^{-}$which diffuses into the bentonite causing calcite precipitation and a decrease of $\mathrm{pH}$. This can be seen in the low $\mathrm{pH}$ computed near the granite-bentonite interface (Fig. 17). $\mathrm{pH}$ is buffered by calcite dissolution-precipitation and especially by surface protonation reactions. Figure 18 shows the patterns of calcite dissolution-precipitation.

The $\mathrm{pH}$ calculated with a model without surface complexation (Fig. 17) is much larger than that computed with the base model in which $\mathrm{pH}$ is stabilized at a much lower value, especially near the bentonite-granite interface. Clearly, the $\mathrm{pH}$ is greatly buffered by protonation on the surface complexes. This is consistent with the findings of Zheng et al. (2010). Although Fig.17 shows that the model without protonation leads to a better fit to inferred data, it is not 
tenable to argue that protonation should not be included. The evolution of $\mathrm{pH}$ is the result of the combined effect of several chemical reactions. A proper judgment of whether protonation should be included could be enforced if the model can consider the uncertainties in: 1) The initial $\mathrm{pH}$ of bentonite pore water and 2) The degassing of $\mathrm{CO}_{2(\mathrm{~g})}$ from the liquid which is not taken into account in the model. The $\mathrm{CO}_{2(\mathrm{~g})}$ released near the heater could migrate through the gas phase and redissolve in the condensation zone. $\mathrm{CO}_{2(\mathrm{~g})}$ degassing and dissolution affect $\mathrm{pH}$, dissolved $\mathrm{HCO}_{3}{ }^{-}$and calcite dissolution and precipitation.

The initial volume fraction of anhydrite is zero. Anhydrite starts to precipitate after heating because anhydrite is more stable than gypsum for temperatures above $43{ }^{\circ} \mathrm{C}$. At 1827 days, near the granite-bentonite interface, the initially precipitated anhydrite is dissolved and near the heater there is still some anhydrite (Fig. 19). When heater 1 was switched off after 1827 days, the bentonite barrier was cooled and anhydrite dissolved due to the decrease in temperature. Gypsum shows a trend just opposite to that of anhydrite. All the gypsum was dissolved before cooling ( $\mathrm{t}<1827$ days). Anhydrite converted into gypsum near the heater after cooling at 1930 days (Fig. 20).

Bentonite hydration increases its porosity near the bentonite-granite interface due to swelling and decreases the porosity near the heater due to thermal shrinkage (see Figure 8). Bentonite porosity may change also due to mineral dissolution/precipitation. The contributions of chemical reactions and thermal and mechanical phenomena to changes in the bentonite porosity are shown in Figure 21. Clearly, the changes in porosity caused by chemical reactions after 1930 days are negligible. They are an order of magnitude smaller than those produced by swelling and shrinkage. Therefore, the effect of the chemical reactions on the porosity of the bentonite is minimal for the duration of the FEBEX in situ test. 
The inferred concentrations of chemical species in the bentonite decrease near the heaterbentonite interface after reaching a plateau at $r=0.7 \mathrm{~m}$. This reduction occurs not only for $\mathrm{Cl}^{-}$ but also for other reactive species such $\mathrm{Ca}^{2+}$. Computed concentrations near the heater, which are controlled mainly by the evaporation of pore water and mineral precipitation, show a trend which is opposite to that of measured data. Mineral precipitation cannot explain such a decrease (see Figure 11 for $\mathrm{Ca}^{2+}$. Further analyses are needed to find possible reasons for this discrepancy such as the solute redistribution during the cooling period between 1827 and 1930 days. Available data from small-scale heating and hydration cell experiments, however, do not exhibit the same behavior as the in situ test (Zheng et al., 2010).

\subsection{Discussion}

\subsubsection{Relevance of chemical osmosis}

The key parameter for chemical osmosis is the reflection coefficient. Keijzer et al. (1999) and Keijzer and Loch (2001) reported reflection coefficients from 0.001 to 0.3 for compacted Na-bentonite and from 0.015 to 0.03 for Wyoming bentonite. Soler (2001) used a reflection coefficient of 0.1 for Opalinus clay. A reflection coefficient of 0.2 was adopted here for the base model (see Table 2).

According to Equations (4) and (5), the chemical osmotic pressure depends on the ionic strength of the solution which varies from 0.01 at the bentonite-granite interface to $0.3 \mathrm{~mol} / \mathrm{L}$ near the heater (Fig.22). Also shown in Fig. 22 is the ratio of the osmotic pressure to the liquid pressure. For the most part, this ratio is around 0.02, showing that the water flux induced by the chemical osmosis is much less relevant than the Darcian water flux. As illustrated in Fig 9, the 
water contents computed by disregarding chemical osmosis are indistinguishable from those of the base model.

\subsubsection{Relevance of thermal osmosis}

Thermal osmosis has been reported to be relevant for fluid flow in shales (Ghassemi and Diek, 2002) and clay formations (Dirksen, 1969; Srivastava and Avasthi, 1975; Soler, 1999). There are few experimental data on thermo-osmotic permeability, $k_{T}$. The range from $10^{-14}$ to $10^{-}$ ${ }^{10} \mathrm{~m}^{2} / \mathrm{K} / \mathrm{s}$ (Soler, 2001) probably brackets most of the published data such as $5.4 \cdot 10^{-12} \mathrm{~m}^{2} / \mathrm{K} / \mathrm{s}$ from Zhou et al. (1999) and $6 \cdot 10^{-11} \mathrm{~m}^{2} / \mathrm{K} / \mathrm{s}$ from Ghassemi and Diek (2002). For FEBEX bentonite, Chen et al. (2009) used a value of $4 \cdot 10^{-12} \mathrm{~m}^{2} / \mathrm{K} / \mathrm{s}$ in a THM model of the in situ test. Zheng and Samper (2008) calibrated a $k_{T}$ of $3.62 \cdot 10^{-12} \mathrm{~m}^{2} / \mathrm{K} / \mathrm{s}$ for the FEBEX mockup test and Zheng et al. (2010) obtained a value of $4 \cdot 10^{-12} \mathrm{~m}^{2} / \mathrm{K} / \mathrm{s}$ from a small-scale experiment. In our base model, $k_{T}$ is equal to $5.2 \cdot 10^{-12} \mathrm{~m}^{2} / \mathrm{K} / \mathrm{s}$, which is slightly larger than the values mentioned above because our permeability is also slightly larger than the permeability of Chen et al. (2009).

Figure 9 shows the computed water contents for several values of $k_{T}$. Computed water contents are remarkably sensitive to changes in $k_{T}$ by a factor of 2.The sensitivity analysis results shown in Table 5 illustrate the importance of $k_{T}$ for the gravimetric water content in comparison with the intrinsic permeability and the vapor tortuosity. Relative changes in the parameters (CP) were computed as $\left|\frac{P_{c}-P_{b}}{P_{b}}\right| \times 100$ while the relative change in the water content (AS) was calculated as $\sum_{i}^{n}\left|\frac{V_{c}^{i}-V_{b}^{i}}{V_{b}^{i}}\right| \times 100$, where $\mathrm{P}_{\mathrm{c}}$ and $\mathrm{P}_{\mathrm{b}}$ are the parameters used in the sensitivity and the base runs, respectively, $V_{c}$ and $V_{b}$, are the computed values in the sensitivity and the base runs, 
respectively, and $n$ is the total number of nodes. The relative sensitivity was computed as $\frac{A S}{C P}$. Computed water contents are most sensitive to the intrinsic permeability and then to the thermal osmotic permeability.

\subsubsection{Parameters affecting $\mathrm{Cl}^{-}$concentration}

Hydrodynamic as well as transport parameters affect the computed $\mathrm{Cl}^{-}$concentrations. Therefore, the sensitivity of the computed $\mathrm{Cl}^{-}$concentrations at 1930 days was evaluated for the intrinsic permeability, the thermal osmotic permeability, the vapor tortuosity, the effective diffusion and the initial $\mathrm{Cl}^{-}$concentration. Model results of $\mathrm{Cl}^{-}$at 1930 days were computed for the interval $0.46 \mathrm{~m}<\mathrm{r}<1.5 \mathrm{~m}$ which includes the bentonite barrier and about $0.4 \mathrm{~m}$ of granite. Tables 6 and 7 summarize the results of the sensitivity runs. The computed spatial distribution of dissolved $\mathrm{Cl}^{-}$is most sensitive to the intrinsic permeability. Changes in the thermal osmotic permeability, the effective diffusion and the initial $\mathrm{Cl}^{-}$concentration also affect significantly the computed $\mathrm{Cl}^{-}$concentrations.

Figure 10 shows the computed $\mathrm{Cl}^{-}$concentrations for several values of the initial $\mathrm{Cl}^{-}$ concentration. An intitial concentration of $0.24 \mathrm{~mol} / \mathrm{L}$ provides the best fit to inferred aqueous extract data at sections 19 and 29.

\subsubsection{Relevance of the initial pore water composition}

There are uncertainties in the initial concentrations of the chemical species because geochemical models are used to infer the initial pore water composition of the bentonite at the initial water content of $14 \%$ from aqueous extract data obtained at a high liquid-to-solid ratio. 
The pore water compositions derived from squeezing and aqueous extract methods are generally different. The model presented here relies on the pore water composition inferred by Fernández (2001) from aqueous extract data. Let $C_{a q}^{i}$ be the concentrations derived from aqueous extract data. On the other hand, Zheng et al. (2008a) inferred the pore water composition of bentonite at a water content of $14 \%$ from squeezing data (see Table 5). Such composition is denoted here as $C_{s q}^{i}$. The sensitivity of computed concentrations of chemical species to the initial composition of the bentonite pore water was evaluated by comparing the model results obtained with $C_{a q}^{i}$ and $C_{s q}^{i}$. The results of both runs are compared in Figure $11 \mathrm{for}^{2{ }^{2+}}$, Figure 12 for $\mathrm{Mg}^{2+}$, Fig. 12), Figure 13 for $\mathrm{Na}^{+}$, Figure 15 for $\mathrm{SO}_{4}{ }^{2-}$ and Figure 16 for $\mathrm{HCO}_{3}{ }^{-}$. Model results are clearly sensitive to the initial concentrations. The use of the $C_{a q}^{i}$ concentrations leads to computed concentrations of $\mathrm{Ca}^{2+}$ and $\mathrm{SO}_{4}{ }^{2-}$ which are larger than those computed with $C_{s q}^{i}$. In the base run, anhydrite precipitates near the heater due to the large $\mathrm{Ca}^{2+}$ and $\mathrm{SO}_{4}{ }^{2-}$ concentrations caused by evaporation. On the other hand, anhydrite does not precipitate in the sensitivity run $\left(C_{s q}^{i}\right)$ because the initial concentrations of $\mathrm{Ca}^{2+}$ and $\mathrm{SO}_{4}{ }^{2-}$ are lower than those of the base run. Thus, the differences in the initial concentrations of $\mathrm{Ca}^{2+}$ and $\mathrm{SO}_{4}{ }^{2-}$ not only cause differences in the computed concentration at 1930 days, but lead also to differences in the spatial patterns of concentrations (see Figures 11 and 15). Such differences are also observed for $\mathrm{Mg}^{2+}, \mathrm{Na}^{+}$and $\mathrm{HCO}_{3}{ }^{-}$(Figures 12, 13 and 16). 


\section{CONCLUSIONS}

Safety assessment of a geological repository for radioactive waste requires quantifying the geochemical evolution of the engineered barrier where thermal, hydrodynamic, mechanical and chemical phenomena show strong interplays. A coupled THC model of the FEBEX in situ test with bentonite swelling and chemical and thermal osmosis has been presented. The model confirms: (1) The importance of bentonite swelling for the spatial distribution of conservative and reactive chemical species due to its effect on porosity; (2) The relevance of thermal osmosis; (3) The lack of relevance of chemical osmosis; (4) The importance of calcite dissolutionprecipitation and cation exchange reactions on the concentrations of dissolved cations; and (5) The strong effect of gypsum/anhydrite dissolution-precipitation on the geochemical evolution of the bentonite barrier.

Sensitivity analyses indicate that water contents and dissolved concentrations are strongly sensitive to the intrinsic permeability and the thermal osmotic permeability. Computed concentrations are very sensitive to the initial concentrations because changes in the initial concentrations not only cause differences in the computed concentration, but lead also to differences in the spatial patterns of concentrations of dissolves species and mineral phases.

For the most part, the model reproduces the measured temperature, relative humidity, water content and inferred geochemical data. However, model results deviate from measured data at the heater-bentonite and bentonite-granite interfaces, possibly because the model fails to account for the volume change of bentonite, $\mathrm{CO}_{2}(\mathrm{~g})$ degassing and vapor transport from bentonite to granite. The inferred $\mathrm{HCO}_{3}{ }^{-}$and $\mathrm{pH}$ data cannot be explained by solute transport, calcite dissolution and protonation/deprotonation accounted in the model, showing that other chemical reactions might be relevant. 


\section{ACKNOWLEDGEMENTS}

This research work was carried out within the framework of the FEBEX project with funding from ENRESA and the European Union through contracts FI4W-CT95-0006 and FIKW-CT2000-00016 of the Nuclear Fission Program. During the preparation of manuscript, the first author was supported by a project funded by the US Environmental Protection Agency, the Office of Water and Office of Air and Radiation under an Interagency Agreement with the U.S. Department of Energy at the Lawrence Berkeley National Laboratory, Contract No. DE-AC0205CH11231. Funding for the most recent work has been provided by the PEBS project from the European Commission (FP7-232632) and a project from Xunta de Galicia (10MDS118028PR). We are grateful to the three anonymous reviewers for their evaluations, comments and recommendations. All of them were pertinent and improved the paper.

\section{Appendix A}

This appendix presents the governing equations of the model which are similar to those reported by Zheng et al. (2010) for a small-scale heating and hydration experiment performed on FEBEX bentonite.

\section{Water Mass Balance}

The water mass balance is given by (Navarro and Alonso, 2000):

$$
\frac{D_{s} m^{w}}{D t}+m^{w} \nabla \cdot \mathbf{v}^{s}+\nabla \cdot\left(\rho^{l} X_{l}^{w} \mathbf{q}^{l}+\rho^{g} X_{g}^{v} \mathbf{q}^{g}+\mathbf{j}^{v}\right)=0
$$


where $D_{s}() / D t$ is the material derivative with respect to the solid particles which move with a velocity vector $\mathbf{v}^{s}(\mathrm{~m} / \mathrm{s}), \nabla \cdot()$ is the divergence operator, $\rho^{l}$ and $\rho^{g}$ are the bulk densities of the liquid and gaseous phases $\left(\mathrm{kg} / \mathrm{m}^{3}\right)$, respectively, $X_{l}^{w}$ is the mass fraction of water in the liquid phase, $X_{g}^{v}$ is the mass fraction of the vapor in the gas phase, $\mathbf{q}^{l}$ is the vector of volumetric liquid flux (m/s), $\mathbf{q}^{g}$ is the vector of volumetric gas flux $(\mathrm{m} / \mathrm{s}), \mathbf{j}^{v}$ is the dispersive mass flux of vapor with respect to the mean gas velocity $\left(\mathrm{kg} / \mathrm{m}^{2} / \mathrm{s}\right)$ and $m^{\mathrm{w}}$ is the mass of water per unit volume of porous medium $\left(\mathrm{kg} / \mathrm{m}^{3}\right)$.

\section{Air mass balance}

The air mass balance equation is given by (Navarro and Alonso, 2000):

$$
\frac{D_{s} m^{a}}{D t}+m^{a} \nabla \cdot \mathbf{v}^{s}+\nabla \cdot\left[X_{g}^{a} \rho^{g} \mathbf{q}^{g}+X_{l}^{a} \rho^{l} \mathbf{q}^{l}\right]=0
$$

where $X_{g}^{a}$ is the mass fraction of air in the gaseous phase, $X_{l}^{a}$ is the mass fraction of air in the liquid phase, and $m^{a}$ is the mass of air per unit volume of porous medium $\left(\mathrm{kg} / \mathrm{m}^{3}\right)$.

\section{Energy balance}

The formulation assumes that all phases and species are at local thermal equilibrium and therefore they are all at the same temperature. Hence, the energy balance is described in terms of an equation of internal energy which is defined by the following balance of enthalpy:

$$
\frac{D_{s} h}{D t}+h \nabla \cdot \mathbf{v}^{s}+\nabla \cdot\left(-\boldsymbol{\Lambda} \cdot \nabla T+\mathbf{I}^{e}\right)=0
$$

where $h$ is the average specific enthalpy of the soil $(\mathrm{J} / \mathrm{kg})$ which in turn is given by:

$$
h=\rho^{l} X_{l}^{w} \phi S_{l} h^{w}+\rho^{g} X_{g}^{v} \phi\left(1-S_{l}\right) h^{v}+\rho^{g} X_{g}^{a} \phi\left(1-S_{l}\right) h^{a}+\rho^{l} X_{l}^{a} \phi S_{l} h^{a}+\rho^{s}(1-\phi) h^{s}
$$


where $h^{w}, h^{v}, h^{a}$ and $h^{s}$ are the specific enthalpies of free water, vapor, air and solid particles respectively, which are assumed to depend linearly on temperature and specific heat (Navarro and Alonso, 2000) and $\mathbf{I}^{e}$ is the vector of convective energy flux which is given by:

$$
\mathbf{I}^{e}=\rho^{l} X_{l}^{w} h^{w} \mathbf{q}^{l}+\rho^{g} X_{g}^{v} h^{v} \mathbf{q}^{v}+\rho^{g} X_{g}^{a} h^{a} \mathbf{q}^{g}
$$

where $\mathbf{q}^{g}$ is the vector of volumetric vapor flux (m/s) which is given by the last terms of Eq. (1), that is, $\mathbf{q}^{v}=\rho^{g} X_{g}^{v} \mathbf{q}^{g}+\mathbf{j}^{v}$ and $\boldsymbol{\Lambda}$ is the bulk thermal conductivity tensor $\left(\mathrm{W} / \mathrm{m} \cdot{ }^{\circ} \mathrm{C}\right)$ which for unsaturated bentonite is computed as a volume-weighted average of the conductivities of the components according to:

$$
\boldsymbol{\Lambda}=\phi S_{l} \boldsymbol{\Lambda}^{w}+\phi\left(1-S_{l}\right)\left(\boldsymbol{\Lambda}^{v}+\boldsymbol{\Lambda}^{a}\right)+X_{l}^{a} \phi S_{l} \boldsymbol{\Lambda}^{a}+(1-\phi) \boldsymbol{\Lambda}^{s}
$$

where $\boldsymbol{\Lambda}^{w}, \boldsymbol{\Lambda}^{v}, \boldsymbol{\Lambda}^{a}$ and $\boldsymbol{\Lambda}^{s}$ are the thermal conductivities of water, vapor, air and solid, respectively. This equation is inspired in the formulation of De Vries's (1963) which according to Tang et al. (2008) provides the best fit to measured thermal conductivity data for several bentonites, including the FEBEX bentonite. The formulation in Eq. (6), however, may not be appropriate for courser porous materials.

\section{Mechanical Equilibrium Equation}

The following incremental formulation of the equilibrium equation of Navarro and Alonso (2000) is used:

$$
\nabla \cdot\left(\Delta \mathbf{\sigma}^{\prime}+\Delta \mathrm{p}^{\mathrm{g}} \delta\right)+\Delta \rho \mathrm{g} \mathbf{k}=0
$$

where $\Delta \rho$ is the increment of the average soil density, $\mathrm{g}$ is the gravitational acceleration $\left(\mathrm{m} / \mathrm{s}^{2}\right)$, $\mathbf{k}$ is the unit vector in the gravity direction, $\boldsymbol{\delta}$ is the vector expression of Kronecker's delta, $\Delta \mathrm{p}^{\mathrm{g}}$ is the increment in gas pressure (Pa) which for saturated conditions should be replaced by $\Delta p^{l}$ the increment in liquid pressure (Pa) and $\Delta \boldsymbol{\sigma}$ 'is the vector of increments of effective stress (Pa) 
which is related to the vector of increments of total stress $\Delta \boldsymbol{\sigma}(\mathrm{Pa})$ in unsaturated conditions through:

$$
\Delta \boldsymbol{\sigma}^{\prime}=\Delta \boldsymbol{\sigma}-\Delta p^{g} \delta
$$

while for saturated conditions the previous equation is replaced by $\Delta \boldsymbol{\sigma}^{\prime}=\Delta \boldsymbol{\sigma}-\Delta p^{l} \delta$ (Fredlund and Rahardjo, 1993).

\section{Solute transport}

Solute transport takes place by advection, molecular diffusion, and mechanical dispersion. There are as many transport equations as primary chemical species in the system, $N_{\mathrm{c}}$. The mass balance equation for the j-th primary species is given by (Zheng and Samper, 2008):

$$
m_{l}^{w} \frac{\partial C_{j}}{\partial t}+\frac{\partial\left(m_{l}^{w} P_{j}\right)}{\partial t}+\frac{\partial\left(m_{l}^{w} W_{j}\right)}{\partial t}+\frac{\partial\left(m_{l}^{w} Y_{j}\right)}{\partial t}=L^{*}\left(C_{j}\right)+r_{i}\left(C_{j}^{0}-C_{j}\right) \mathrm{j}=1,2, \ldots \mathrm{N}_{\mathrm{c}}
$$

$C_{j}$ is the total dissolved concentration of the of $\mathrm{j}$-th species $(\mathrm{mol} / \mathrm{L}), m_{l}^{w}$ is the mass of liquid water per unit volume of medium $\left(\mathrm{kg} / \mathrm{m}^{3}\right)$ which is equal to $\rho^{l} X_{l}^{w} \theta$ where $\theta=S_{l} \phi$ is the volumetric water content $\left(\mathrm{m}^{3} / \mathrm{m}^{3}\right), \mathrm{P}_{\mathrm{j}}, \mathrm{Y}_{\mathrm{j}}$ and $\mathrm{W}_{\mathrm{j}}$ are the total precipitated, sorbed and exchanged concentrations (mol/L), respectively, of the $j$-th primary species, $r_{i}$ is the sink term $\left(\mathrm{kg} / \mathrm{m}^{2} / \mathrm{s}\right), \mathrm{C}_{j}^{0}$ is the dissolved concentration of $\mathrm{j}$-th species $(\mathrm{mol} / \mathrm{L})$ in the sink term $r_{i}$, and $L^{*}()$ is the following transport operator:

$$
\mathrm{L}^{*}()=\nabla \cdot\left[m_{\mathrm{l}}^{\mathrm{w}} \mathbf{D}^{\mathrm{j}} \cdot \nabla()\right]-m_{\mathrm{l}}^{\mathrm{w}} \mathbf{q}^{l} \cdot \nabla()+\left(\mathrm{r}_{\mathrm{e}}-\mathrm{r}_{\mathrm{c}}\right)(\mathrm{)}
$$

where $\mathbf{D}^{j}$ is the dispersion coefficient $\left(\mathrm{m}^{2} / \mathrm{s}\right), \mathrm{r}_{\mathrm{c}}$ and $\mathrm{r}_{\mathrm{e}}$ are the condensation and evaporation rates $\left(\mathrm{kg} / \mathrm{m}^{2} / \mathrm{s}\right)$, respectively.

\section{Mechanical model}

The mechanical law is given by: 


$$
d \boldsymbol{\varepsilon}=\mathbf{C} d \boldsymbol{\sigma}^{\prime}+\boldsymbol{\beta} d \psi+\boldsymbol{\alpha} d T
$$

where $\varepsilon$ is the strain vector, $\mathbf{C}$ is the elastic matrix $(1 / \mathrm{Pa}), \boldsymbol{\beta}$ is a vector of coefficients $(1 / \mathrm{Pa})$ which account for the deformation caused by changes in suction $\psi, \psi=\left(p^{l}-p^{g}\right)$, and $\boldsymbol{\alpha}$ is a vector of thermal expansion coefficients $\left(1 /{ }^{\circ} \mathrm{C}\right)$. The standard sign convention used in Soil Mechanics is adopted here according to which compressions are positive.

\section{REFERENCES}

Alonso EE, J Alcoverro, F Coste, L. Malinskyb, V. Merrien-Soukatchoffc, I. Kadiric, T. Nowakd, H. Shaod, T.S. Nguyene, A.P.S. Selvaduraie, p, G. Armande, p, S.R. Sobolikf, M. Itamuraf, C.M. Stonef, S.W. Webbf, A. Rejebg, M. Tijanih, Z. Maoucheh, A. Kobayashii, H. Kurikamij, A. Itoj, Y. Sugitaj, M Chijimatsuk, L. Börgessonl, J. Hernelindm, J. Rutqvistn, C.-F. Tsangn and P. Jussilao, 2005, The FEBEX benchmark test: case definition and comparison of modeling approaches. Int J Rock Mech Mining Sci 42(5-6): 611-38.

Alonso, E.E., Gens, A. and Josa, A., 1990. A constitutive model for partially saturated soils. Géotechnique, 40(3): 405-430.

Alonso, E., Ledesma, A., 2005, Advances in Understanding Engineered Clay Barriers, A. Balkema Pub., Leiden, 583 pp.

Alonso, E.E., Vaunat, J. and Gens, A., 1999. Modelling the mechanical behaviour of expansive clays. Engineering Geology, 54: 173-183. 
Arcos, D., Bruno, J., Karnland, O., 2003. Geochemical model of the granite-bentonitegroundwater interaction at Äspö HRL (LOT experiment). Applied Clay Science 23, 219228.

Bradbury, M.H., Baeyens, B., 1997. A mechanistic description of Ni and Zn sorption on Namontmorillonite. Part II: Modelling. J. Contaminant Hydrology, 27, 223-248.

Bradbury, M.H., Baeyens, B., 1998. A physicochemical characterisation and geochemical modelling approach for determining porewater chemistries in argillaceous rocks. Geochim. Cosmochim. Acta, 62: 783-795.

Bradbury, B., Baeyens, B., 2003. Porewater chemistry in compacted resaturated MX-80 bentonite. J. Contaminant Hydrology, 61, 329-338.

Chapuis R.P., Aubertin, M., 2003. On the use of the Kozeny-Carman equation to predict the hydraulic conductivity of soils, Can. Geotech. J. 40(3), 616-628, doi:10.1139/t03-013.

Chatterjee, A., Ebina, T., Onodera, Y. and Mizukami, F., 2004. Effect of exchangeable cation on the swelling property of $2: 1$ dioctahedral smectite - A periodic first principle study. J. Chem. Phys. 120(7), 3414-3424.

Chen Y, C Zhou, and L. Jing, 2009 Modeling coupled THM processes of geological porous media with multiphase flow: theory and validation against laboratory and field scale experiments. Computers and Geotechnics, 36(8): 1308-29.

Cormenzana, J.L., Missana, T., Mingarro, M., 2004. Diffusion coefficients and accessible porosity for HTO and ${ }^{36} \mathrm{Cl}$ in compacted FEBEX bentonite. Applied Clay Science, 26, 65-73.

Dai, Z., Samper, J., 2004. Inverse problem of multicomponent reactive chemical transport in porous media: Formulation and Applications. Water Resources Research, 40, W07407. 
Dirksen, D., 1969. Thermo-osmosis through compacted saturated clay membranes. Soil Sci. Soc. Am. Proc., 33(6): 821-826.

De Vries, D.A., 1963. Thermal properties of soils. In: Van Wijk, W.R. (Ed.), Physics of Plant Environment. North-Holland Publishing Company, Amsterdam, pp. 210-235.

ENRESA, 2000. Full-scale engineered barriers experiment for a deep geological repository in crystalline host rock FEBEX Project. EUR 19147 EN, European Commission.

ENRESA, 2006a. FEBEX: Updated final report. ENRESA Tech. Publ. PT 05-0/2006, 589 pp.

ENRESA, 2006b. FEBEX: Final report on thermo-hydro-mechanical modelling. ENRESA Techn. Publ. PT 05-2/2006, 163 pp.

ENRESA, 2006c. FEBEX: Final THG modelling report. ENRESA Techn. Publ. PT 05-3/2006, 155 pp.

Fernández, A., Cuevas, J., Rivas, P., 2001. Pore water chemistry of the FEBEX bentonite. Mat. Res. Soc. Symp. Proc., 663, 573-588.

Fernández, A.M., Rivas, P., 2003. Task 141: Post-mortem bentonite analysis. Geochemical behaviour. 70-IMA-L-0-107 v0.

Fernández, A.M., Baeyens, B., Bradbury, M., Rivas, P., 2004. Analysis of the pore water chemical composition of a Spanish compacted bentonite used in an engineered barrier. Physics and Chemistry of the Earth 29(1), 105-118.

Fernández, A.M., Rivas, P., 2005. Pore water chemistry of saturated FEBEX bentonite compacted at different densities. In: Alonso, E.E., Ledesma, A. (Eds.), Advances in Understanding Engineered Clay Barriers. A.A. Balkema Publishers, Leiden, The Netherlands, pp 505-514. 
Fredlund, DG. and H Rahardjo, 1993, Soil Mechanics for Unsaturated Soils, Wiley-IEEE, 517 pp.

García-Gutiérrez, M., Cormenzana, J.L., Missana, T., Mingarro, M., Molinero, J., 2006. Overview of laboratory methods employed for obtaining diffusion coefficients in FEBEX compacted bentonite. Journal of Iberian Geology, 32(1), 37-53.

Garrels, R.M. and Christ, C.L., 1965. Solutions, Minerals, and Equilibria. Harper and Row, New York.

Gens, A. and Alonso, E.E., 1992. A framework for the behaviour of unsaturated expansive clays. Canadian Geotechnical Journal, 29: 1013-1032.

Thomas, H.R. and He, Y., 1998. Modelling the behaviour of unsaturated soil using an elastoplastic constitutive model. Géotechnique, 48(5): 589-603.

Ghassemi, A. and Diek, A., 2002. Porothermoelasticity for swelling shales. Journal of Petroleum Science and Engineering, 34: 123-125.

Karnland, O, Sandén, T., Johannesson, L.E., Eriksen, T.E., Janson, M., Wold, S., Pedersen, K., Motamedi, M., Rosborg, B., 2000. Long term test of buffer material. Final report on the pilot parcels. SKB Technical Report 00-22.

Keijzer, T.J.S., Kleingeld, P.J. and J.P.G., L., 1999. Chemical osmosis in compacted clayey material and the prediction of water transport. Engineering geology, 53: 151-159.

Keijzer, T.J.S. and Loch, J.P.G., 2001. Chemical osmosis in compacted dredging sludge. Soil Sci. Soc. Am. J., 65: 1045-1055.

Komine, H. and Ogata, N., 1996. Prediction for swelling characteristics of compacted bentonite. Canadian Geotechnical Journal, 33: 11-22. 
Komine, H. and Ogata, N., 2003. New equations for swelling characteristics of bentonite-based buffer materials. Canadian Geotechnical Journal, 40: 460-475.

Lloret, A., Romero, E., Villar, M.V., 2004. FEBEX II Project Final report on thermohydromechanical laboratory tests. Publicación Técnica ENRESA 10/04, Madrid,180pp.

Lloret, A., Alonso, E.E., 1995. State surfaces for partially saturated soils, In proceedings of the International Conference on Soils Mechanics and Foundation Engineering, Balkema, pp. 557-562.'

Martín, P.L. and J.M. Barcala, 2005, Large scale buffer material test: Mock-up experiment at CIEMAT, Engineering Geology 81, 298- 316.

Martinez-Landa L and J Carrera, 2005, An analysis of hydraulic conductivity scale effects in granite (Full-scale Engineered Barrier Experiment (FEBEX), Grimsel, Switzerland), Water Resources Research, Vol. 41, w03006, 13 pp., doi:10.1029/2004wr003458

Mauran, S., Rigaud, L., Coudevylle, O., 2001. Application of the Carman-Kozeny correlation to a high-porosity and anisotropic consolidated medium: the compressed expanded natural graphite. Transport in Porous Media 43, 355-376.

Navarro, V., Alonso, E.E., 2000. Modeling swelling soils for disposal barriers. Computers and Geotechnics, 27, 19-43.

Nguyen, T.S., Selvadurai, A.P.S., Armand, G., 2005. Modelling the FEBEX THM experiment using a state surface approach. International Journal of Rock Mechanics and Mining Science, 42(5-6), 639-651.

Odong, J., 2007. Evaluation of empirical formulae for determination of hydraulic conductivity based on grain-size analysis, The Journal of American Science. 3(3), 54-60. 
Pearson, F.J., 2003. Geochemistry of water in the Opalinus Clay Formation at the Mont Terri Rock Laboratory. Technical report $N^{0}$ 5, Swiss Federal Office for Water and Geology Series.

Sacchi, E., Michelot, J.L., Pitsch, H., Lalieux, P., Aranyossy, J.F., 2001. Extraction of water and solution from argillaceous rock for geochemical characterisation: methods, processes, and current understanding. Hydrogeology Journal, 9, 17-33.

Salles, F., Bildstein, O., Douillard, J. M., Jullien, M., Raynal, J. and Van Damme, H., 2010. On the Cation Dependence of Interlamellar and Interparticular Water and Swelling in Smectite Clays. Langmuir 26(7), 5028-5037.

Samper, J., Yang, C., Montenegro, L., 2003. CORE ${ }^{2 D}$ version 4: A code for non-isothermal water flow and reactive solute transport. Users Manual. University of La Coruña, Spain.

Samper, J., Zheng, L., Montenegro, L., Fernández, A.M., Rivas, P., 2008a, Coupled thermohydro-chemical models of compacted bentonite after FEBEX in situ test, Applied Geochemistry, 23(5), 1186-1201. doi:10.1016/j.apgeochem.2007.11.010.

Samper, J., Zheng, L., Fernández, A.M., Montenegro, L., 2008b. Inverse modeling of multicomponent reactive transport through single and dual porosity media, Journal of Contaminant Hydrology, 98(3-4), 115-127. 10.1016/j.jconhyd.2008.03.008.

Samper, J., T. Xu and C. Yang, 2009, A sequential partly iterative approach for multicomponent reactive transport with $\mathrm{CORE}^{2 \mathrm{D}}$, Comput Geosci DOI 10.1007/s10596-008-9119-5.

Sánchez, M., A Gens, LJDN Guimarães, and S Olivella, 2005. A double structure generalized plasticity model for expansive materials. International Journal for Numerical and Analytical Methods in Geomechanics, 29: 751-787. 
Sánchez, M, A Gens and S Olivella, 2011. THM analysis of a large-scale heating test incorporating material fabric changes, Int. J. Numer. Anal. Meth. Geomech. DOI: 10.1002/nag.1011.

Schanz, T. and Tripathy, S., 2009. Swelling pressure of a divalent-rich bentonite: Diffuse double-layer theory revisited. Water Resour. Res. 45, W00C12.

SKB, 1983. Final storage of spent nuclear fuel-KBS-3. SKBF/KBS Report.

Soler, J.M., 2001. The effect of coupled transport phenomena in the Opalinus Clay and implications for radionuclide transport. Journal of Contaminant Hydrology, 53: 63-84.

Soltanieh, M. and Gill, W.N., 1981. Review of reverse osmosis membranes and transport models. Chem. Eng.Commun., 12: 279-363.

Tang AM, Cui YJ, Le TT, 2008, A study on the thermal conductivity of compacted bentonites, Applied Clay Science, 41(3-4), 181-189.

Thomas, H.R. and Cleall, P.J., 1999. Inclusion of expansive clay behaviour in coupled thermo hydraulic mechanical models. Engineering Geology, 54: 93-108.

Tsang, C.F., Stephansson, O., Jing, L.R., Kautsky, F., 2009, DECOVALEX Project: from 1992 to 2007. Environmental Geology, 57(6), 1221-1237.

Verstricht, J., Van Humbeeck, H., Li, X.L., De Cannière, P., 2007. Final report on the mock-up "OPHELIE", EIG EURIDICE (European Underground Research Infrastructure for Disposal of nuclear waste In Clay Environment http://www.euridice.be/eng/00home.shtm) .

Villar, M.V., 2004. Task 141: Postmortem bentonite analysis.Version 0. 70-IMA-M-6-7 v0. 
Villar MV, M. Sánchez, A Gens, 2008, Behaviour of a bentonite barrier in the laboratory: Experimental results up to 8 years and numerical simulation, Physics and Chemistry of the Earth 33 (2008) S476-S485.

Wakim, J., Hadj-Hassen, F. and De Windt, L., 2009. Effect of aqueous solution chemistry on the swelling and shrinkage of the Tournemire shale. International Journal of Rock Mechanics and Mining Sciences 46(8), 1378-1382.

Wolery, T.J., 1992. EQ3/6. A software Package for Geochemical modelling of Aqueous Systems: Package Overview and Installation Guide Version 7.0. UCRL-MA-110662-PTI, Lawrance Livermore National Laboratory, Livermore, California.

Xie, M., Agus, S.S., Schanz, T. and Kolditz, O., 2004. An upscaling method and a numerical analysis of swelling/shrinking processes in a compacted bentonite/sand mixture. International Journal for Numerical and Analytical Methods in Geomechanics, 28: 14791502.

Zheng, L., Samper, J., 2004. Formulation of the inverse problem of non-isothermal multiphase flow and reactive transport in porous media, In Computer Methods in Water Resources XV, pp. 1317-1327.

Zheng, L., Samper, J., 2005. Inverse problem of non-isothermal multiphase flow and reactive transport in deformable porous media. In: J. Samper and A. Paz González (Editors), VII Jornadas de Investigación en la Zona no Saturada de Suelo, ZNS'05, La Coruña, Spain, pp. 307-313.

Zheng, L., Samper, J., 2008. Coupled THMC model of FEBEX mock up test. Physics and Chemistry of the Earth. 33, S486-S498, doi:10.1016/j.pce.2008.10.023. 
Zheng, L., Samper, J., Montenegro, L., 2008a. Inverse hydrochemical models of aqueous extract experiments, Physics and Chemistry of the Earth, 33(12-13), 1009-1018, doi:10.1016/j.pce.2008.05.012.

Zheng, L., Samper, J., Montenegro, L., Mayor, J.C., 2008b. Flow and reactive transport model of a ventilation experiment in Opallinus clay. Phys. Chem. Earth 33 (14-16), 1009-1018. doi:10.1016/j.pce.2008.05.012.

Zheng, L., Samper, J., Montenegro, L., Fernández., A.M., 2010. A coupled THMC model of a heating and hydration laboratory experiment in unsaturated compacted FEBEX bentonite. Journal of Hydrology, 386(1-4), 80-94.

Zhou, Y., Rajapakse, R.K.N.D. and Graham, J., 1999. Coupled Field in a deformable unsaturated medium. International Journal of Solid and Structures, 36: 4841-4868.

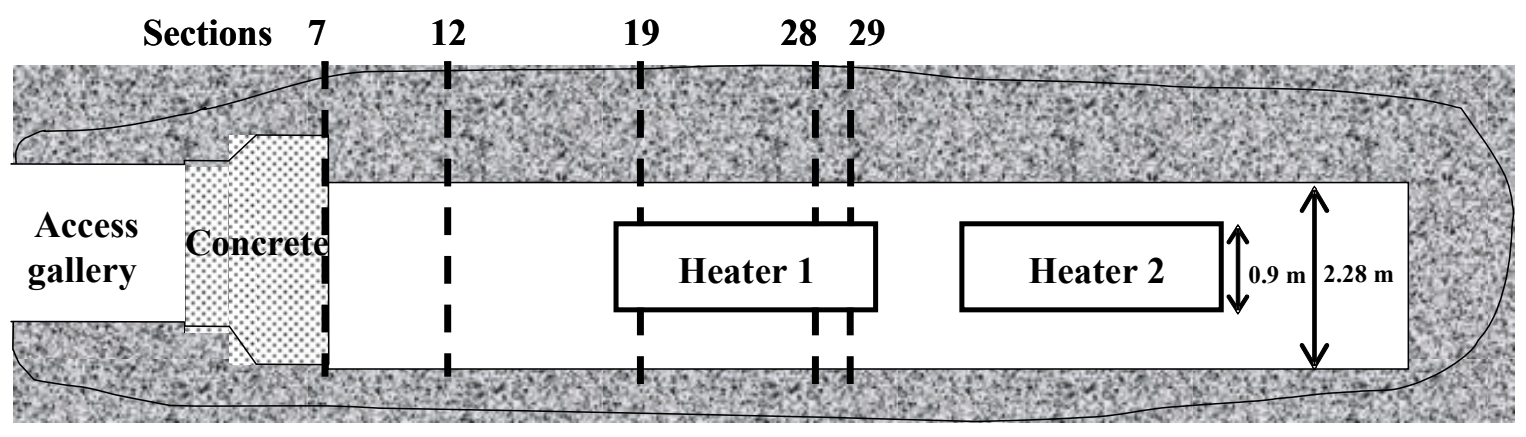

Fig. 1. Layout of the FEBEX in situ test. Vertical lines show the location of the sampling sections (Samper et al., 2008a). 


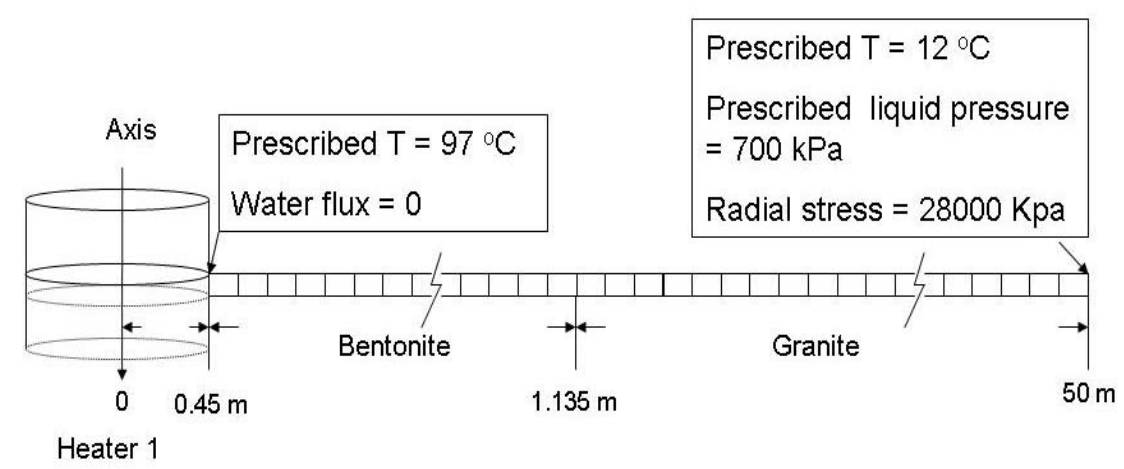

Fig. 2. Finite element mesh and boundary conditions used in the numerical model (Samper et al., 2008a).

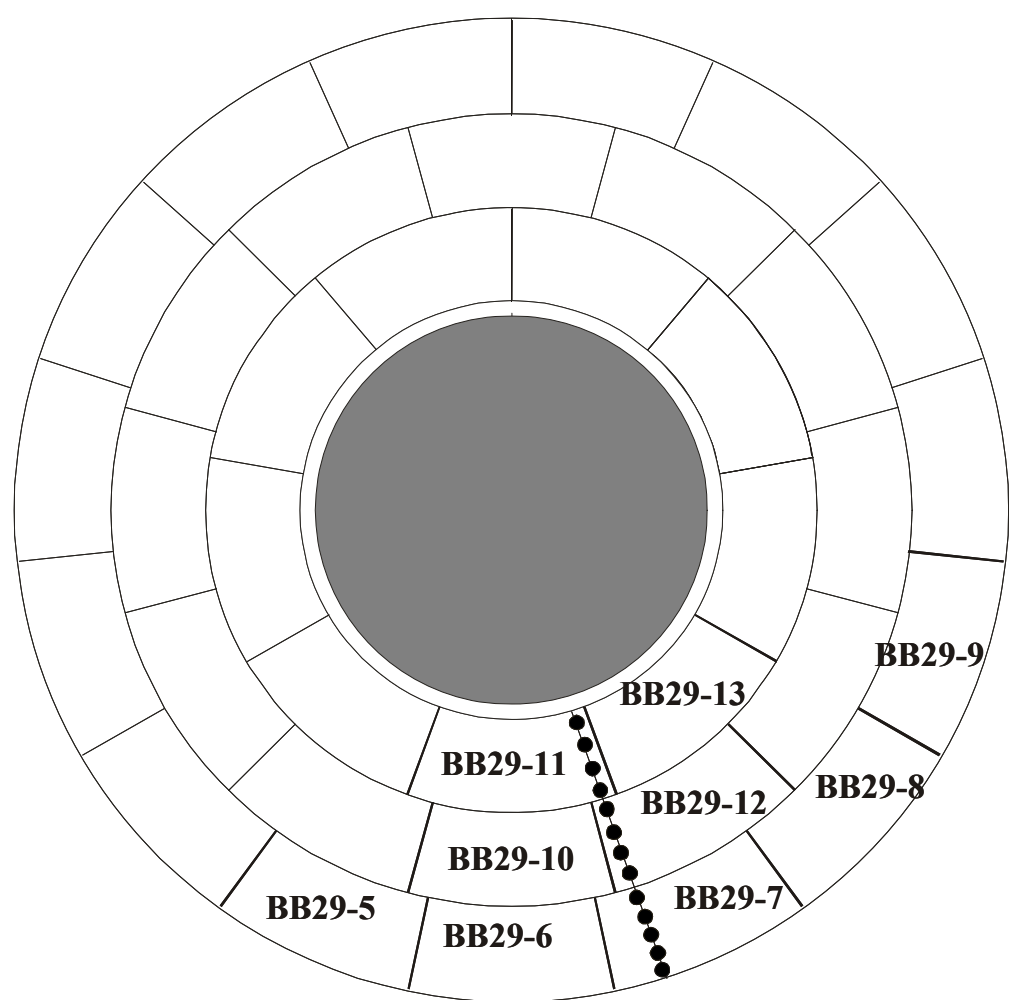

Fig. 3. Location of the bentonite blocks BB29-5 to BB-29-13 used for chemical analyses after dismantling section 29 of the FEBEX in situ test (Samper et al., 2008a). 


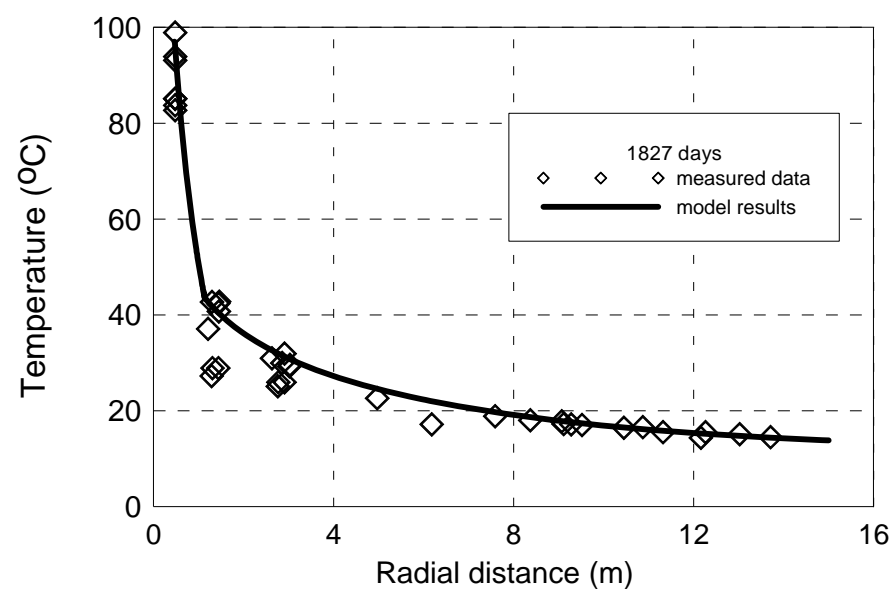

Fig. 4. Comparison of computed and measured radial distribution of temperature after 1827 days of heating when heater 1 was switched off (Samper et al., 2008a).

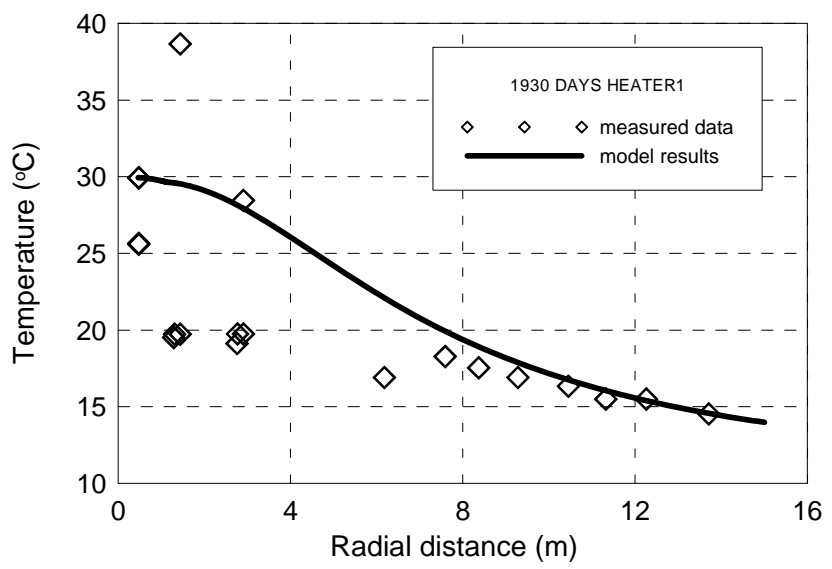

Fig. 5. Comparison of computed and measured radial distribution of temperature after 1930 days when dismantling was performed (Samper et al., 2008a).

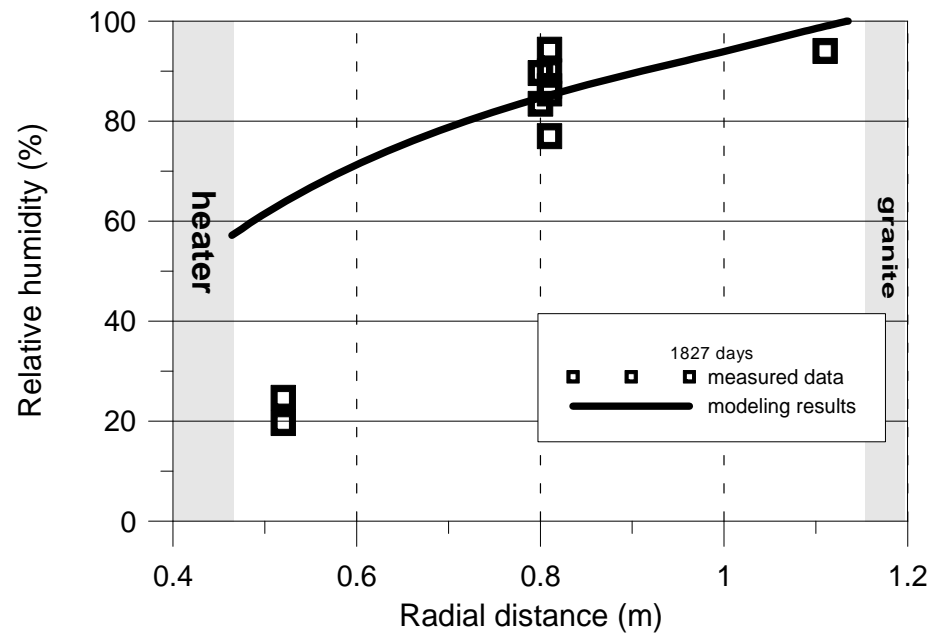

Fig. 6. Comparison of computed and measured radial distribution of relative humidities after 1827 days. 


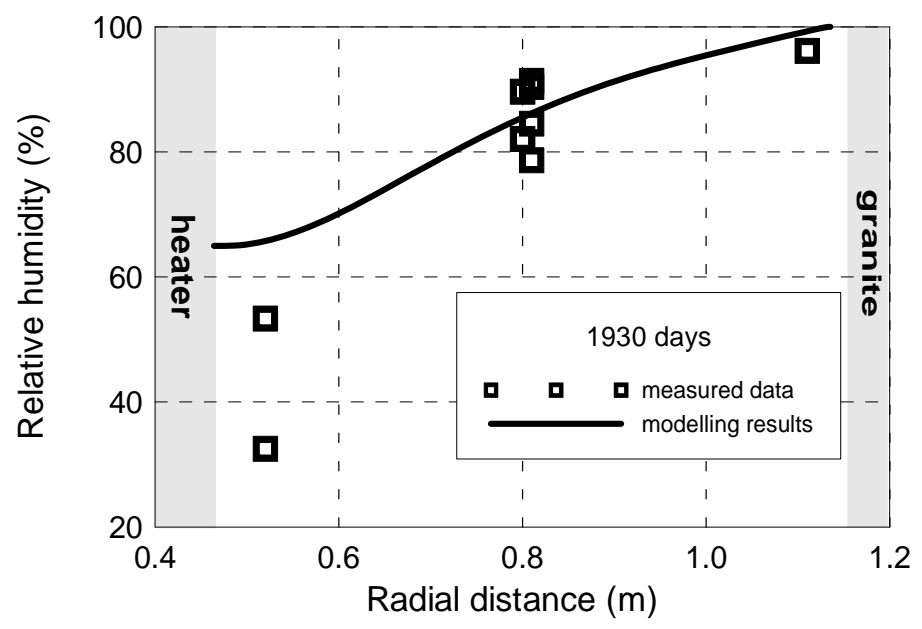

Fig. 7. Comparison of computed and measured radial distribution of relative humidities after 1930 days.

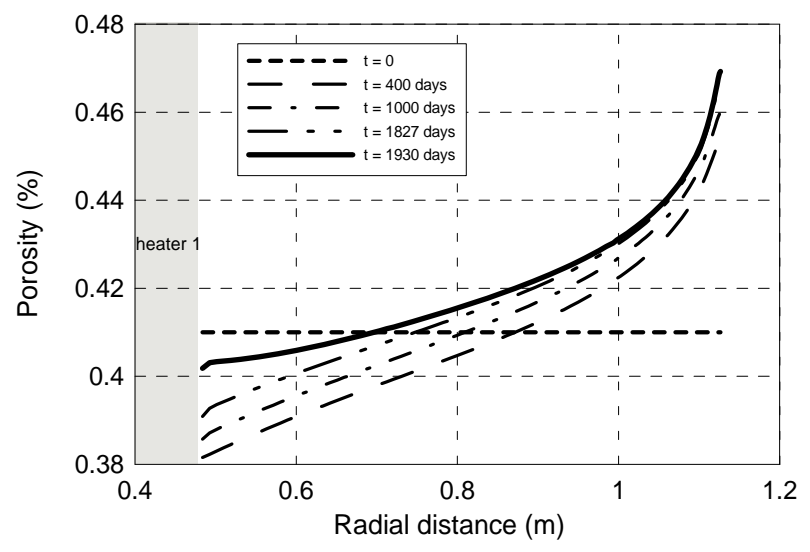

Fig. 8. Computed radial distribution of porosity at selected times.

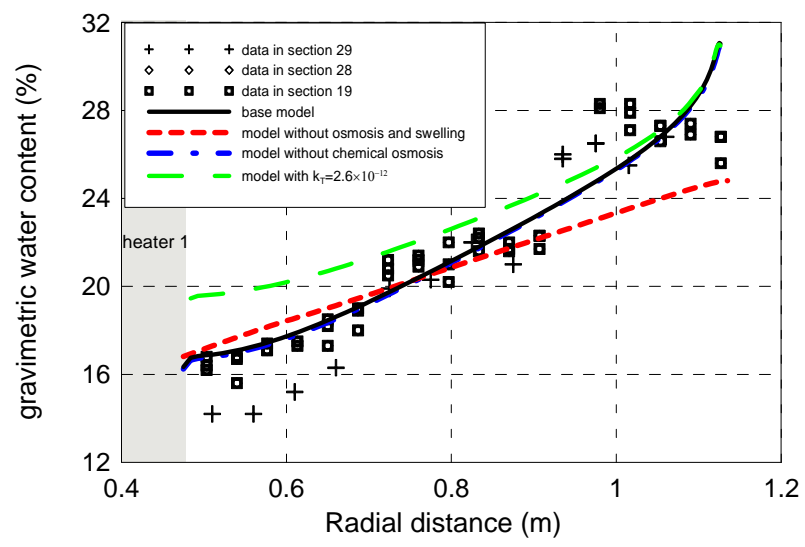

Fig. 9. Radial distribution of measured (symbols) and computed water contents after 1930 days. Models results are shown for several combinations of processes and for a sensitivity run with a thermal osmotic permeability of $2.6 \times 10^{-12} \mathrm{~m}^{2} / \mathrm{K} / \mathrm{s}$ equal to half the value of the base model. 




Fig. 10. Computed (lines) and inferred $\mathrm{Cl}^{-}$concentrations at sections 19 and 29 (symbols) after 1930 days. Computed concentrations are shown for several values of the initial concentrations $\left(\mathrm{C}_{\mathrm{i}}\right)$ in addition to the base run model $\left(\mathrm{C}_{\mathrm{i}}=0.16 \mathrm{~mol} / \mathrm{L}\right)$ and a model which disregards thermal osmosis and swelling.

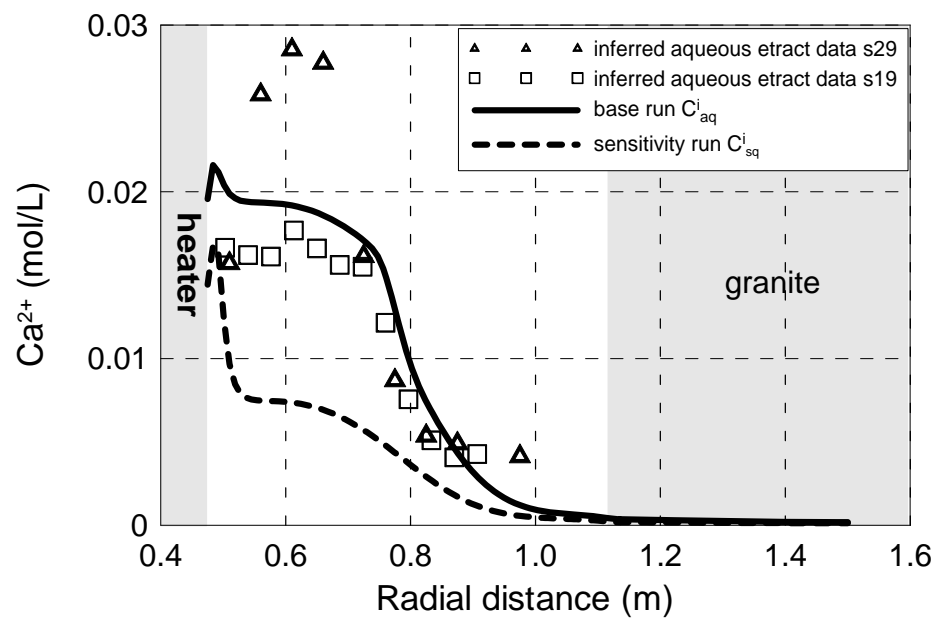

Fig. 11. Computed (lines) and inferred $\mathrm{Ca}^{2+}$ concentrations at sections 19 and 29 (symbols) after 1930 days. Computed concentrations are shown for two initial concentrations: $C_{a q}^{i}$ and $C_{s q}^{i}$. 


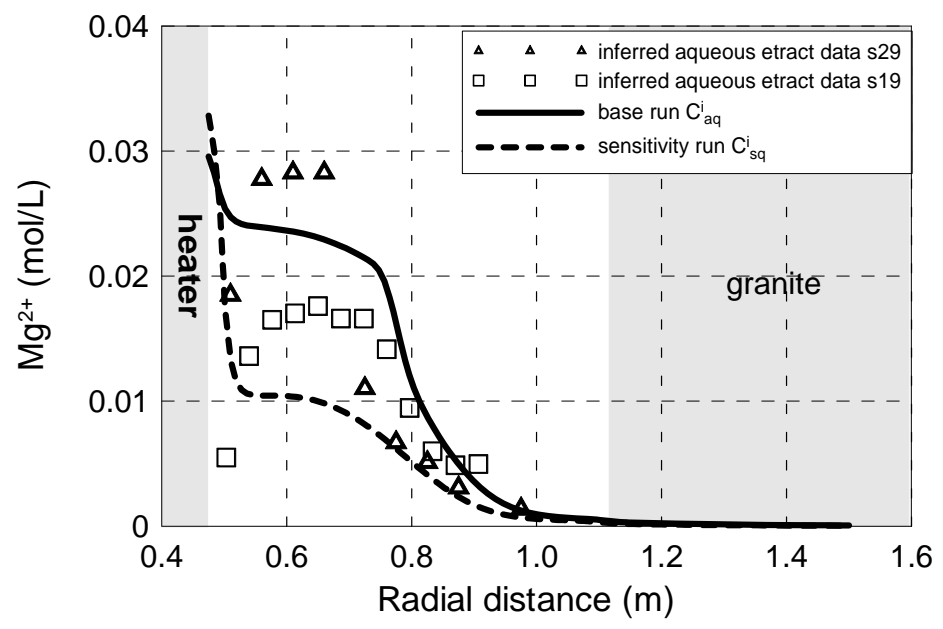

Fig. 12. Computed (lines) and inferred $\mathrm{Mg}^{2+}$ concentrations at sections 19 and 29 (symbols) after 1930 days. Computed concentrations are shown for two initial concentrations: $C_{a q}^{i}$ and $C_{s q}^{i}$.



Fig. 13. Computed (lines) and inferred $\mathrm{Na}^{+}$concentrations at sections 19 and 29 (symbols) after 1930 days. Computed concentrations are shown for two initial concentrations: $C_{a q}^{i}$ and $C_{s q}^{i}$. 


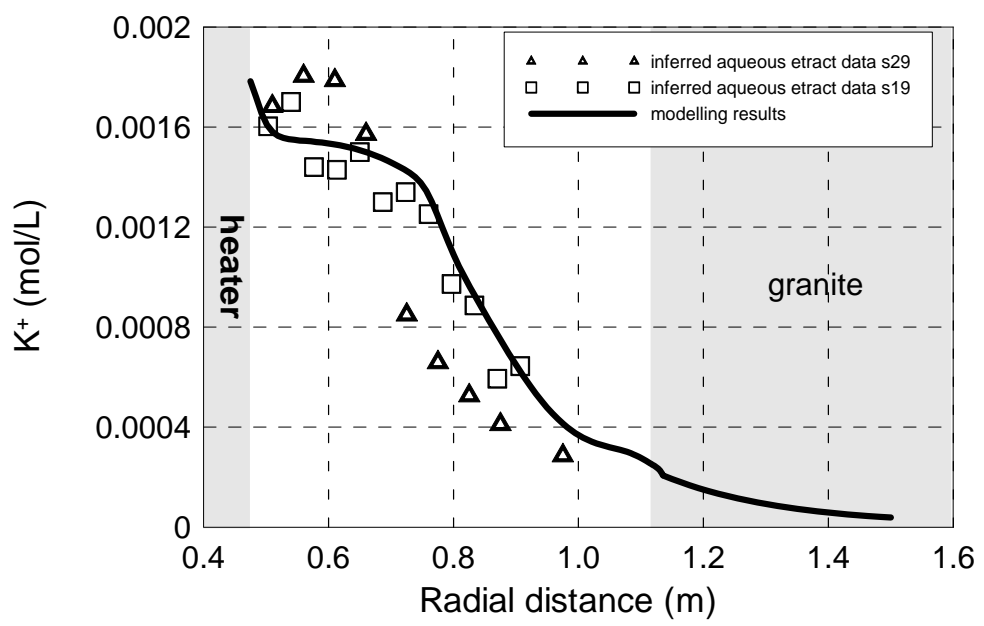

Fig. 14. Computed (lines) and inferred $\mathrm{K}^{+}$concentrations at sections 19 and 29 (symbols) after 1930 days. Computed concentrations are shown for two initial concentrations: $C_{a q}^{i}$ and $C_{s q}^{i}$.

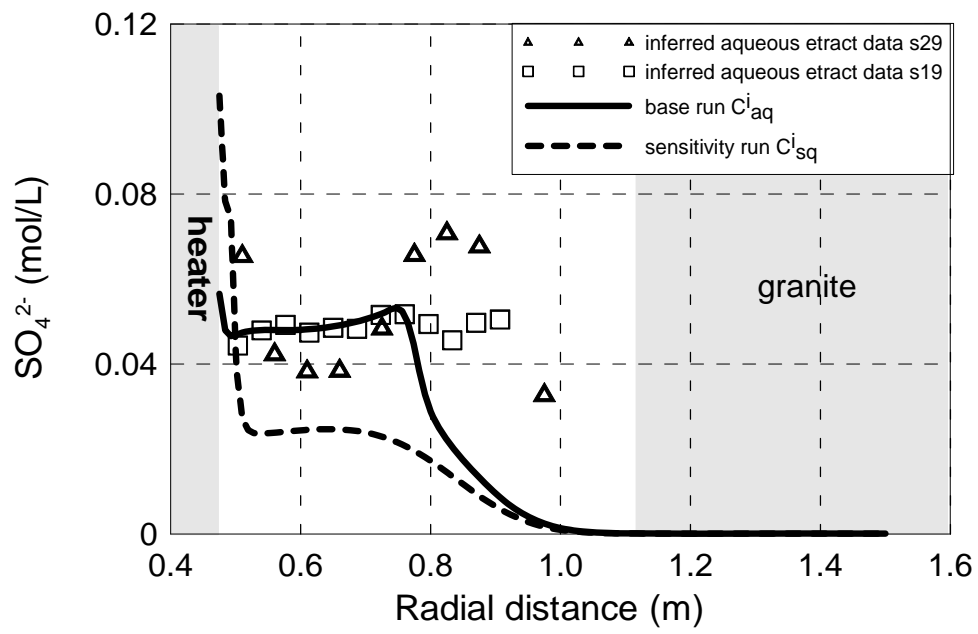

Fig. 15. Computed (lines) and inferred $\mathrm{SO}_{4}{ }^{2-}$ concentrations at sections 19 and 29 (symbols) after 1930 days. Computed concentrations are shown for two initial concentrations: $C_{a q}^{i}$ and $C_{s q}^{i}$. 


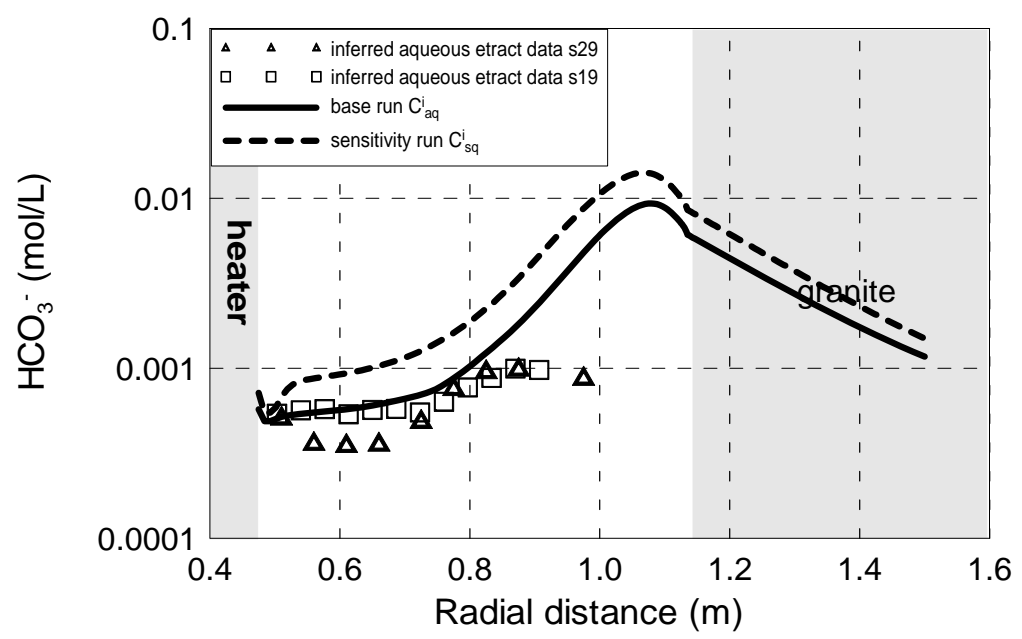

Fig. 16. Computed (lines) and inferred $\mathrm{HCO}_{3}{ }^{-}$concentrations at sections 19 and 29 (symbols) after 1930 days. Computed concentrations are shown for two initial concentrations: $C_{a q}^{i}$ and $C_{s q}^{i}$.

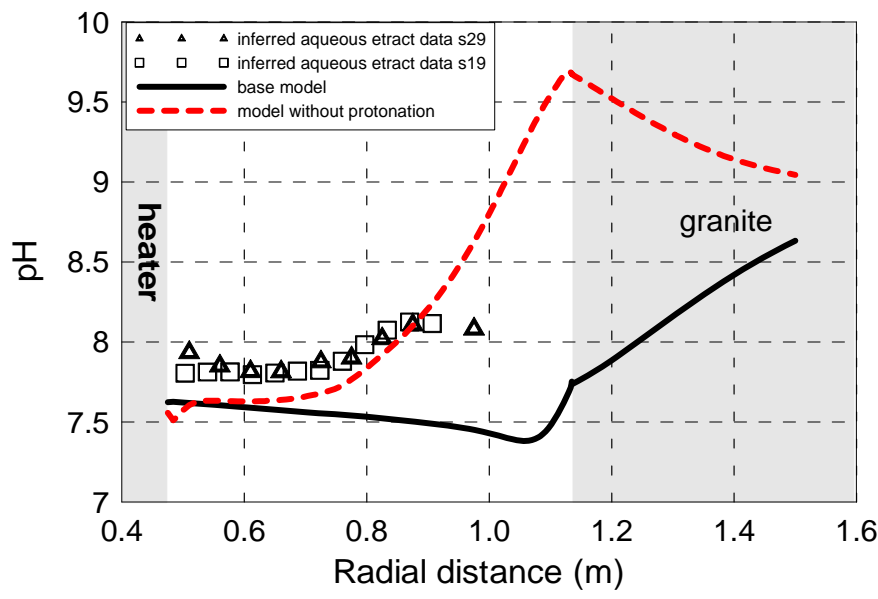

Fig. 17. Computed (lines) and inferred pH at sections 19 and 29 (symbols) after 1930 days. Model results are shown for the base model and a model without protonation by surface complexation. 


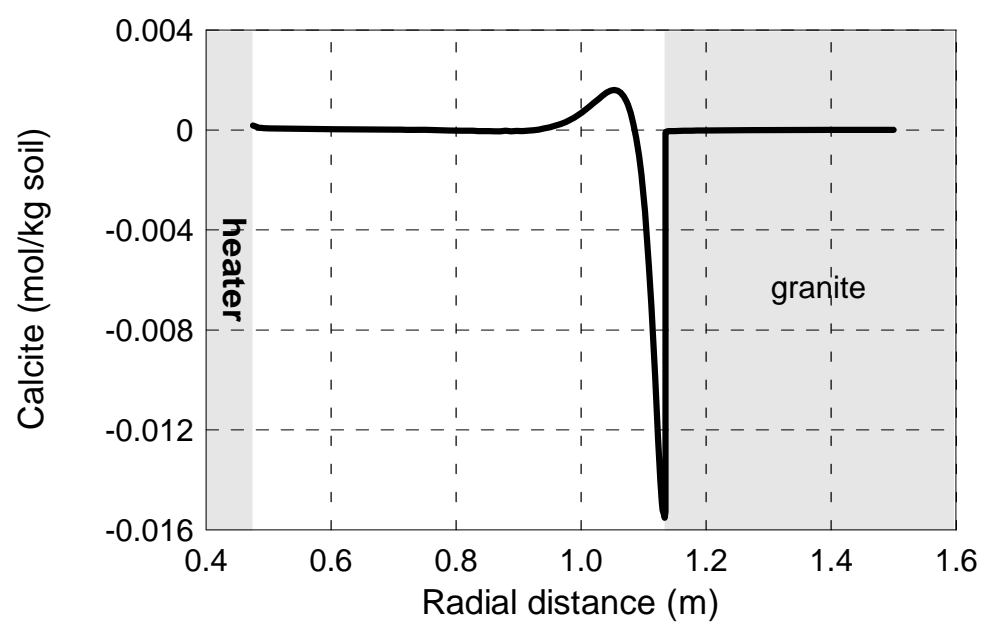

Fig. 18. Computed spatial distribution of cumulative calcite dissolution-precipitation after 1930 days. Negative values indicate dissolution while positive values designate precipitation.

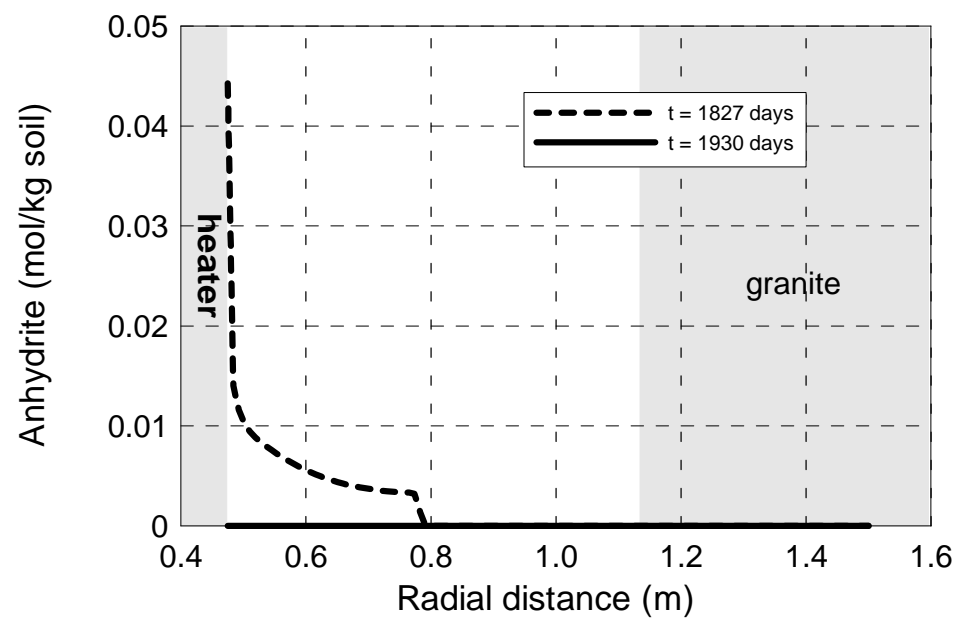

Fig. 19. Computed spatial distribution of cumulative anhydrite precipitation after 1827 and 1930 days. 


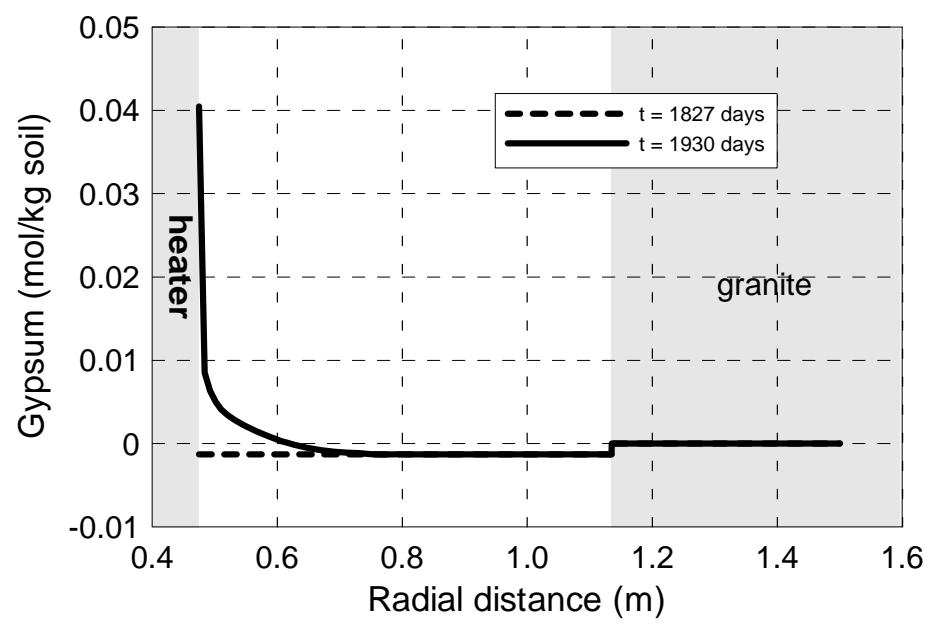

Fig. 20. Computed spatial distribution of cumulative gypsum dissolution-precipitation after 1827 and 1930 days. Negative values indicate dissolution while positive values designate precipitation.

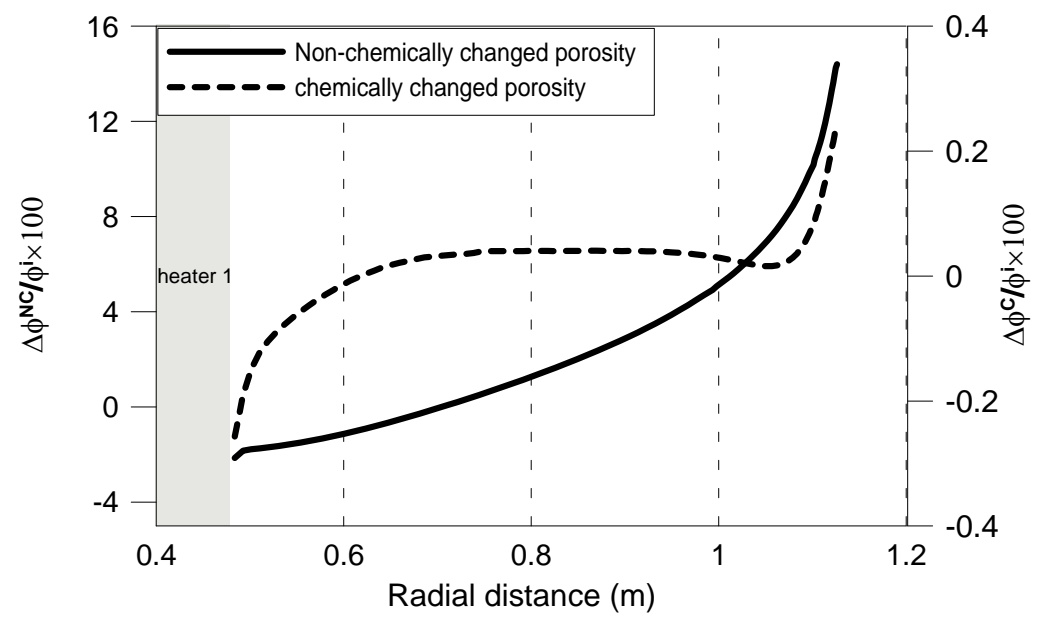

Fig. 21. Relative changes in porosity caused by non-chemical processes, $\Delta \phi^{N C} / \phi^{i} \times 100$, swelling and thermal shrinkage) and chemical reactions (mineral precipitation/dissolution), $\Delta \phi^{C} / \phi^{i} \times 100$, after 1930 days. $\phi^{i}$ is the initial porosity, $\Delta \phi^{N C}$ is the change in porosity caused by non-chemical processes and $\Delta \phi^{C}$ is the change caused by chemical reactions. 


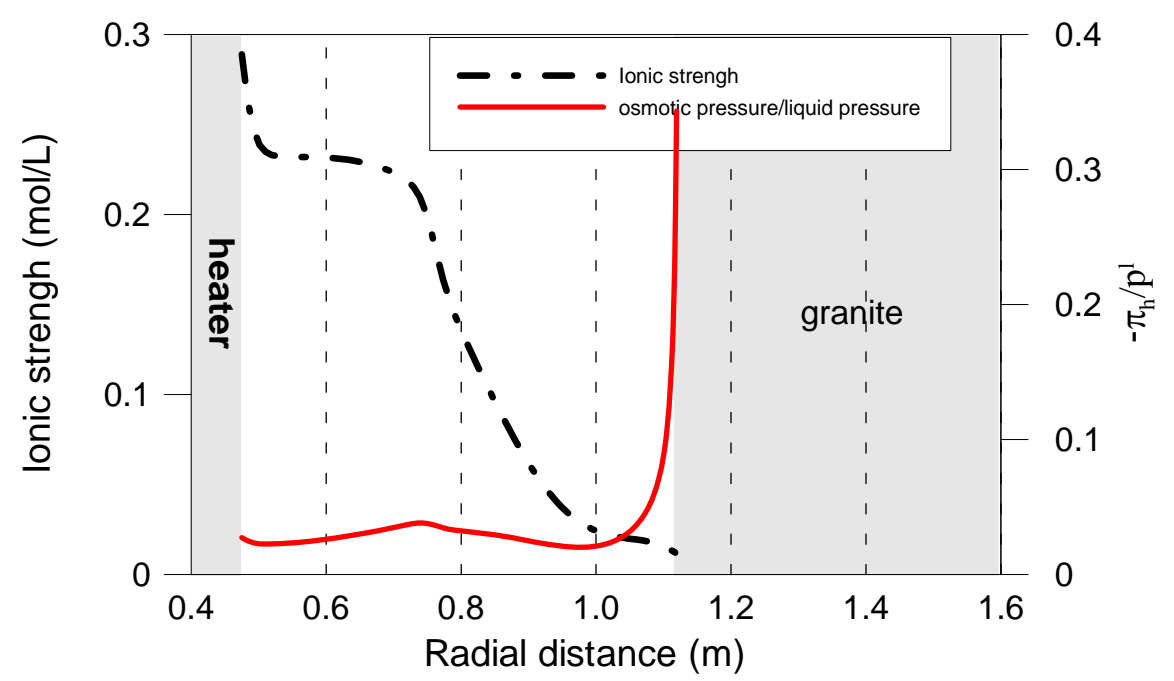

Fig. 22. Radial distribution of the ionic strength and the ratio of the osmotic pressure to the liquid pressure $\left(-\pi_{h} / p^{l}\right)$ after 1930 days. 
Table 1. Equilibrium constants for aqueous complexes and minerals (Wolery, 1992), selectivity coefficients for cation exchange reactions (ENRESA, 2006c; Samper et al., 2008a,c; Zheng and Samper, 2008), and protolysis constants for surface complexation reactions for a triple-site model (Bradbury and Baeyens, 1997) at $25^{\circ} \mathrm{C}$.

\begin{tabular}{|c|c|}
\hline Aqueous complexes & $\log \mathrm{K}\left(25^{\circ} \mathrm{C}\right)$ \\
\hline $\mathrm{CaCl}^{+} \Leftrightarrow \mathrm{Ca}^{2+}+\mathrm{Cl}^{-}$ & 0.70457 \\
\hline $\mathrm{CaCO}_{3}(\mathrm{aq})+\mathrm{H}^{+} \Leftrightarrow \mathrm{Ca}^{2+}+\mathrm{HCO}_{3}^{-}$ & 7.1009 \\
\hline $\mathrm{CaHCO}_{3}^{+} \Leftrightarrow \mathrm{Ca}^{2+}+\mathrm{HCO}_{3}^{-}$ & -1.04111 \\
\hline $\mathrm{CaSO}_{4}(\mathrm{aq}) \Leftrightarrow \mathrm{Ca}^{2+}+\mathrm{SO}_{4}^{2-}$ & -2.0855 \\
\hline $\mathrm{CO}_{2}(\mathrm{aq})+\mathrm{H}_{2} \mathrm{O} \Leftrightarrow \mathrm{H}^{+}+\mathrm{HCO}_{3}^{-}$ & -6.3733 \\
\hline $\mathrm{CO}_{3}{ }^{2-}+\mathrm{H}^{+} \Leftrightarrow \mathrm{HCO}_{3}^{-}$ & 10.371 \\
\hline $\mathrm{H}_{3} \mathrm{SiO}_{4}^{-}+\mathrm{H}^{+} \Leftrightarrow 2 \mathrm{H}_{2} \mathrm{O}+\mathrm{SiO}_{2}(\mathrm{aq})$ & 9.8626 \\
\hline $\mathrm{KSO}_{4}^{-} \Leftrightarrow \mathrm{K}^{+}+\mathrm{SO}_{4}^{2-}$ & -0.86822 \\
\hline $\mathrm{MgCl}^{+} \Leftrightarrow \mathrm{Mg}^{2+}+\mathrm{Cl}^{-}$ & 0.13413 \\
\hline $\mathrm{MgCO}_{3}(\mathrm{aq}) \Leftrightarrow \mathrm{Mg}^{2+}+\mathrm{CO}_{3}^{-2}$ & -7.428 \\
\hline $\mathrm{MgHCO}_{3}^{+} \Leftrightarrow \mathrm{Ca}^{2+}+\mathrm{HCO}_{3}^{-}$ & -1.0295 \\
\hline $\mathrm{MgSO}_{4}(\mathrm{aq}) \Leftrightarrow \mathrm{Mg}^{2+}+\mathrm{SO}_{4}{ }^{2-}$ & -2.3228 \\
\hline $\mathrm{NaHCO}_{3}(\mathrm{aq}) \Leftrightarrow \mathrm{Na}^{+}+\mathrm{HCO}_{3}^{-}$ & -0.2118 \\
\hline $\mathrm{NaSO}_{4}^{-} \Leftrightarrow \mathrm{Na}^{+}+\mathrm{SO}_{4}^{2-}$ & -0.79855 \\
\hline $\mathrm{OH}^{-}+\mathrm{H}^{+} \Leftrightarrow \mathrm{H}_{2} \mathrm{O}$ & 14.16 \\
\hline Minerals & $\log \mathrm{K}\left(25^{\circ} \mathrm{C}\right)$ \\
\hline $\mathrm{CaCO}_{3}(\mathrm{~s})+\mathrm{H}^{+} \Leftrightarrow \mathrm{Ca}^{2+}+\mathrm{HCO}_{3}^{-}$ & 1.9299 \\
\hline $\mathrm{CaSO}_{4}(\mathrm{~s}) \Leftrightarrow \mathrm{Ca}^{2+}+\mathrm{SO}_{4}^{2-}$ & -4.2451 \\
\hline $\mathrm{CaSO}_{4} \cdot 2 \mathrm{H}_{2} \mathrm{O}(\mathrm{s}) \Leftrightarrow \mathrm{Ca}^{2+}+\mathrm{SO}_{4}{ }^{2-}+2 \mathrm{H}_{2} \mathrm{O}$ & -4.4699 \\
\hline $\mathrm{SiO}_{2}(\mathrm{~s}) \Leftrightarrow \mathrm{SiO}_{2}(\mathrm{aq})$ & -3.8334 \\
\hline Cation exchange & $\mathrm{K}_{\text {Na-cation }}$ \\
\hline $\mathrm{Na}^{+}+\mathrm{X}-\mathrm{K} \Leftrightarrow \mathrm{K}^{+}+\mathrm{X}-\mathrm{Na}$ & 0.138 \\
\hline $\mathrm{Na}^{+}+0.5 \mathrm{X}_{2}-\mathrm{Ca} \Leftrightarrow 0.5 \mathrm{Ca}^{2+}+\mathrm{X}-\mathrm{Na}$ & 0.2942 \\
\hline $\mathrm{Na}^{+}+0.5 \mathrm{X}_{2}-\mathrm{Mg}-\Leftrightarrow 0.5 \mathrm{Mg}^{2+}+\mathrm{X}-\mathrm{Na}$ & 0.2881 \\
\hline Surface complexation reaction & Log $K_{\text {int }}$ \\
\hline$\equiv \mathrm{S}^{\mathrm{S}} \mathrm{OH}^{2+} \Leftrightarrow \equiv \mathrm{S}^{\mathrm{S}} \mathrm{OH}+\mathrm{H}^{+}$ & -4.5 \\
\hline$\equiv \mathrm{S}^{\mathrm{S}} \mathrm{O}^{-} \Leftrightarrow \mathrm{S}^{\mathrm{S}} \mathrm{OH}-\mathrm{H}^{+}$ & 7.9 \\
\hline$\equiv \mathrm{S}^{\mathrm{W} 1} \mathrm{OH}^{2+} \Leftrightarrow \equiv \mathrm{S}^{\mathrm{W} 1} \mathrm{OH}+\mathrm{H}^{+}$ & -4.5 \\
\hline$\equiv \mathrm{S}^{\mathrm{W} 1} \mathrm{O}^{-} \Leftrightarrow \equiv \mathrm{S}^{\mathrm{W} 1} \mathrm{OH}-\mathrm{H}^{+}$ & 7.9 \\
\hline$\equiv \mathrm{S}^{\mathrm{W} 2} \mathrm{OH}^{2+} \Leftrightarrow \equiv \mathrm{S}^{\mathrm{W} 2} \mathrm{OH}+\mathrm{H}^{+}$ & -6.0 \\
\hline$\equiv \mathrm{S}^{\mathrm{W} 2} \mathrm{O}^{-} \Leftrightarrow \equiv \mathrm{S}^{\mathrm{W} 2} \mathrm{OH}-\mathrm{H}^{+}$ & 10.5 \\
\hline
\end{tabular}


Table 2. Hydrodynamic, thermal and mechanical parameters of the bentonite-water system.

\begin{tabular}{|c|c|}
\hline Liquid relative permeability & $k_{r l}=S_{1}^{3}$ \\
\hline Liquid viscosity $(\mathrm{kg} / \mathrm{m} \cdot \mathrm{s})$ & $0.661(T-229)^{-1.562}$ \\
\hline Intrinsic permeability of the gas & $5 \cdot 10^{-10} \mathrm{~m}^{2}$ \\
\hline Relative permeability of the gas & $k_{r l}=\left(1-S_{l}\right)^{3}$ \\
\hline Vapor tortuosity & 0.09 \\
\hline Gas viscosity $(\mathrm{kg} / \mathrm{m} \cdot \mathrm{s})$ & $1.76 \cdot 10^{-5}$ \\
\hline Solid density $\left(\mathrm{kg} / \mathrm{m}^{3}\right)$ & $2780 \cdot e^{\left(-2.10^{-6}(T-12)\right)}$ \\
\hline Reflection coefficient & 0.2 \\
\hline Thermo-osmosis permeability $\left(\mathrm{m}^{2} / \mathrm{K} / \mathrm{s}\right)$ & $5.2 \cdot 10^{-12}$ \\
\hline Specific heat of the liquid $\left(\mathrm{J} / \mathrm{kg} \cdot{ }^{\circ} \mathrm{C}\right)$ & 4202 \\
\hline Specific heat of the air $\left(\mathrm{J} / \mathrm{kg} \cdot{ }^{\circ} \mathrm{C}\right)$ & 1000 \\
\hline Specific heat of the vapor $\left(\mathrm{J} / \mathrm{kg} \cdot{ }^{\circ} \mathrm{C}\right)$ & 1620 \\
\hline Specific heat of the solid $\left(\mathrm{J} / \mathrm{kg} \cdot{ }^{\circ} \mathrm{C}\right)$ & 835.5 \\
\hline Thermal conductivity of the liquid $\left(\mathrm{W} / \mathrm{m}^{\circ}{ }^{\circ} \mathrm{C}\right)$ & 1.5 \\
\hline Thermal conductivity of the air $\left(\mathrm{W} / \mathrm{m} \cdot{ }^{\circ} \mathrm{C}\right)$ & $2.6 \cdot 10^{-2}$ \\
\hline Thermal conductivity of the vapor $\left(\mathrm{W} / \mathrm{m} \cdot{ }^{\circ} \mathrm{C}\right)$ & $4.2 \cdot 10^{-2}$ \\
\hline Thermal conductivity of the solid $\left(\mathrm{W} / \mathrm{m} \cdot{ }^{\circ} \mathrm{C}\right)$ & 1.23 \\
\hline Vaporization enthalpy (J/kg) & $2.45 \cdot 10^{6}$ \\
\hline Mechanical compressibility of the water $\left(\mathrm{Pa}^{-1}\right)$ & $5.10^{-7}$ \\
\hline Thermal compressibility of the water $\left(\mathrm{K}^{-1}\right)$ & $2.1 \cdot 10^{-4}$ \\
\hline Thermal compressibility of the solid $\left(\mathrm{K}^{-1}\right)$ & $2 \cdot 10^{-5}$ \\
\hline Specific heat of the vapor $\left(\mathrm{J} / \mathrm{kg} \cdot{ }^{\circ} \mathrm{C}\right)$ & 1620 \\
\hline
\end{tabular}


Table 3. Hydrodynamic, thermal and mechanical parameters of the granite-water system.

\begin{tabular}{|c|c|}
\hline Intrinsic permeability of the liquid $\left(\mathrm{m}^{2}\right)$ & $8 \cdot 10^{18}$ \\
\hline Relative permeability of the liquid & $k_{r l}=\sqrt{S_{l}}\left[1-\left(1-S_{l}^{0.5}\right)^{0.5}\right]^{2}$ \\
\hline Retention curve & $S_{l}=1 /\left(\left(1+\left(4.76 \cdot 10^{-4} \psi\right)^{1 / 0.3}\right)^{0.7}\right.$ \\
\hline Liquid viscosity $(\mathrm{kg} / \mathrm{m} \cdot \mathrm{s})$ & $0.661(T-229)^{-1.562}$ \\
\hline Solid density $\left(\mathrm{kg} / \mathrm{m}^{3}\right)$ & $2700 \cdot e^{\left(-2.10^{-6}(T-\text { Tref })\right)}$ with $T_{r e f}=12{ }^{\circ} \mathrm{C}$ \\
\hline Porosity & 0.01 \\
\hline Thermal conductivity of the liquid $\left(\mathrm{W} / \mathrm{m}^{\circ}{ }^{\circ} \mathrm{C}\right)$ & 1.5 \\
\hline Specific heat of the liquid $\left(\mathrm{J} / \mathrm{kg} \cdot{ }^{\circ} \mathrm{C}\right)$ & 4202 \\
\hline Thermal conductivity of the solid $\left(\mathrm{W} / \mathrm{m}^{\circ}{ }^{\circ} \mathrm{C}\right)$ & 1.5 \\
\hline Specific heat of the solid $\left(\mathrm{J} / \mathrm{kg} \cdot{ }^{\circ} \mathrm{C}\right)$ & 1029 \\
\hline
\end{tabular}

Table 4. Initial chemical composition of the bentonite and granite pore waters (Samper et al., 2005), initial mineral volume fractions of the bentonite and the granite (Samper et al., 2008), cation exchange composition (Fernández et al., 2004) and site capacities for surface complexation for the triple-site (strong and two weak sites) model (Bradbury and Baeyens, 2003, 2005).

\begin{tabular}{|c|c|c|}
\hline & Bentonite & Granite \\
\hline $\mathrm{pH}$ & 7.72 & 8.35 \\
\hline $\mathrm{Na}^{+}(\mathrm{mol} / \mathrm{kg})$ & $1.3 \cdot 10^{-2}$ & $3.8 \cdot 10^{-4}$ \\
\hline $\mathrm{K}^{+}(\mathrm{mol} / \mathrm{kg})$ & $1.7 \cdot 10^{-3}$ & $7.8 \cdot 10^{-6}$ \\
\hline $\mathrm{Ca}^{2+}(\mathrm{mol} / \mathrm{kg})$ & $2.2 \cdot 10^{-2}$ & $1.8 \cdot 10^{-4}$ \\
\hline $\mathrm{Mg}^{2+}(\mathrm{mol} / \mathrm{kg})$ & $2.3 \cdot 10^{-2}$ & $1.3 \cdot 10^{-6}$ \\
\hline $\mathrm{HCO}_{3}{ }^{-}(\mathrm{mol} / \mathrm{kg})$ & $4.1 \cdot 10^{-4}$ & $7.9 \cdot 10^{-4}$ \\
\hline $\mathrm{SO}_{4}{ }^{-}(\mathrm{mol} / \mathrm{kg})$ & $3.2 \cdot 10^{-2}$ & $1.3 \cdot 10^{-5}$ \\
\hline $\mathrm{Cl}^{-}(\mathrm{mol} / \mathrm{kg})$ & $1.6 \cdot 10^{-1}$ & $1.4 \cdot 10^{-4}$ \\
\hline $\mathrm{SiO}_{2(\mathrm{aq})}(\mathrm{mol} / \mathrm{kg})$ & $1.1 \cdot 10^{-4}$ & 5 \\
\hline $\mathrm{Calcite}(\% \mathrm{vol})_{\mathrm{Chalcedony}(\% \mathrm{vol})}$ & 1 & 20 \\
\hline $\mathrm{Anhydrite}(\% \mathrm{vol})^{\mathrm{Gypsum}(\% \mathrm{vol})}$ & 4.5 & 0 \\
\hline $\mathrm{Na}^{+}(\mathrm{meq} / 100 \mathrm{~g})$ & 0 & 0 \\
\hline $\mathrm{K}^{+}(\mathrm{meq} / 100 \mathrm{~g})$ & 0.016 & - \\
\hline $\mathrm{Ca}^{2+}(\mathrm{meq} / 100 \mathrm{~g})$ & 31.18 & - \\
\hline $\mathrm{Mg}^{2+}(\mathrm{meq} / 100 \mathrm{~g})$ & 1.94 & - \\
\hline$\equiv \mathrm{S}^{\mathrm{S}} \mathrm{OH}(\mathrm{mol} / \mathrm{kg})$ & 34.62 & - \\
\hline
\end{tabular}




\begin{tabular}{|c|c|c|}
\hline$\equiv \mathrm{S}^{\mathrm{W} 1} \mathrm{OH}(\mathrm{mol} / \mathrm{kg})$ & $4.0 \cdot 10^{-3}$ & - \\
\hline$\equiv \mathrm{S}^{\mathrm{W} 2} \mathrm{OH}(\mathrm{mol} / \mathrm{kg})$ & $4.0 \cdot 10^{-3}$ & - \\
\hline
\end{tabular}

Table 5. Sensitivity analyses of water content to changes in the intrinsic permeability, thermal osmotic permeability and vapor tortuosity.

\begin{tabular}{ccccccc}
\hline \multirow{2}{*}{ Parameters } & \multicolumn{2}{c}{ Intrinsic permeability $\left(\mathrm{m}^{2}\right)$} & \multicolumn{2}{c}{$\begin{array}{c}\text { Thermal osmotic } \\
\text { permeability }\left(\mathrm{m}^{2} / \mathrm{K} / \mathrm{s}\right)\end{array}$} & \multicolumn{2}{c}{ Vapor tortuosity } \\
\cline { 2 - 6 } & $1.875 \cdot 10^{-21}$ & $5.625 \cdot 10^{-21}$ & $2.6 \cdot 10^{-12}$ & $7.8 \cdot 10^{-12}$ & 0.045 & 0.18 \\
\hline $\begin{array}{c}\text { Relative change } \\
(\%)\end{array}$ & $-50 \%$ & $50 \%$ & $-50 \%$ & $50 \%$ & $-50 \%$ & $100 \%$ \\
\hline $\begin{array}{c}\text { Relative } \\
\text { sensitivity (\%) }\end{array}$ & 33.27 & 15.69 & 12.75 & 12.23 & 1.09 & 1.28 \\
\hline
\end{tabular}

Table 6. Sensitivity analyses of $\mathrm{Cl}^{-}$concentration to changes in the intrinsic permeability, thermal osmotic permeability and vapor tortuosity.

\begin{tabular}{ccccccc}
\hline \multirow{2}{*}{ Parameters } & \multicolumn{2}{c}{ Intrinsic permeability $\left(\mathrm{m}^{2}\right)$} & \multicolumn{2}{c}{ Thermal osmotic } & \multicolumn{2}{c}{ Vermeability $\left(\mathrm{m}^{2} / \mathrm{K} / \mathrm{s}\right)$} \\
\cline { 2 - 6 } & $1.875 \cdot 10^{-21}$ & $5.625 \cdot 10^{-21}$ & $2.6 \cdot 10^{-12}$ & $7.8 \cdot 10^{-12}$ & 0.045 & 0.18 \\
\hline $\begin{array}{c}\text { Relative change } \\
(\%)\end{array}$ & $-50 \%$ & $50 \%$ & $-50 \%$ & $50 \%$ & $-50 \%$ & $100 \%$ \\
\hline $\begin{array}{c}\text { Relative } \\
\text { sensitivity (\%) }\end{array}$ & 1355.88 & 136.73 & 79.00 & 98.22 & 15.80 & 19.87 \\
\hline
\end{tabular}

Table 7. Sensitivity analyses of $\mathrm{Cl}^{-}$to the intrinsic permeability, thermal osmotic permeability and vapor tortuosity.

\begin{tabular}{ccccc}
\hline \multirow{2}{*}{ Parameters } & \multicolumn{2}{c}{$\begin{array}{c}\text { Initial concentration } \\
(\mathrm{mol} / \mathrm{L})\end{array}$} & \multicolumn{2}{c}{$\begin{array}{c}\text { Effective diffusion } \\
\left(\mathrm{m}^{2} / \mathrm{s}\right)\end{array}$} \\
\cline { 2 - 5 } & 0.24 & 0.08 & $2.6 \cdot 10^{-12}$ & $7.8 \cdot 10^{-12}$ \\
\hline $\begin{array}{c}\text { Relative change } \\
(\%)\end{array}$ & $50 \%$ & $-50 \%$ & $50 \%$ & $100 \%$ \\
\hline $\begin{array}{c}\text { Relative } \\
\text { sensitivity (\%) }\end{array}$ & 153.84 & 153.83 & 59.07 & 81.44 \\
\hline
\end{tabular}


Table 8. FEBEX bentonite pore water composition at water a content of $13.3 \%$ estimated from squeezing data (Samper et al., 2005b). Units in mol/L.

\begin{tabular}{ccccccccc}
\hline Component & $\mathrm{Cl}^{-}$ & $\mathrm{SO}_{4}{ }^{2-}$ & $\mathrm{HCO}_{3}{ }^{-}$ & $\mathrm{Ca}^{2+}$ & $\mathrm{Mg}^{2+}$ & $\mathrm{Na}^{+}$ & $\mathrm{K}^{+}$ & $\mathrm{pH}$ \\
\hline Concentration & $1.87 \cdot 10^{-1}$ & $2.12 \cdot 10^{-2}$ & $6.65 \cdot 10^{-4}$ & $1.14 \cdot 10^{-2}$ & $1.44 \cdot 10^{-2}$ & $1.88 \cdot 10^{-1}$ & $1.68 \cdot 10^{-3}$ & 7.86 \\
\hline
\end{tabular}




\section{DISCLAIMER}

This document was prepared as an account of work sponsored by the United States Government. While this document is believed to contain correct information, neither the United States Government nor any agency thereof, nor the Regents of the University of California, nor any of their employees, makes any warranty, express or implied, or assumes any legal responsibility for the accuracy, completeness, or usefulness of any information, apparatus, product, or process disclosed, or represents that its use would not infringe privately owned rights. Reference herein to any specific commercial product, process, or service by its trade name, trademark, manufacturer, or otherwise, does not necessarily constitute or imply its endorsement, recommendation, or favoring by the United States Government or any agency thereof, or the Regents of the University of California. The views and opinions of authors expressed herein do not necessarily state or reflect those of the United States Government or any agency thereof or the Regents of the University of California. 